\title{
LAS TORRES PUERTA DE EUROPA, MADRID-ESPAÑA
}

\author{
(THE "PUERTA DE EUROPA" TWIN TOWERS, MADRID - SPAIN)
}

Tomás Domínguez del Castillo y Juan Carlos Martín Baranda, Arquitectos; Jesús Lizarbe Teres, Aparejador; Jesús J. Mateos Hdez-Briz, Ing. de Caminos

ESPAÑA

Fecha de recepción: $28-$ VI -96

$131-152$

\begin{abstract}
RESUMEN
La funcionalidad preside el conjunto urbanistico formado por las dos torres situadas al final del Paseo de la Castellana.

Con una inclinación de $15^{\circ}$ sobre su vertical y hacia un punto común, dicho conjunto arquitectónico destaca, sobre todo, por su ubicación, diseño de instalaciones y servicios.

Se destaca la complejidad de su sistema estructural que, unida a la alta tecnología empleada en su construcción, dificultaron la consecución del proyecto.

Las torres Puerta de Europa, destinadas al alquiler de oficinas, son unos edificios cuya terminación -con la diversidad de materiales constructivos empleados- constituye, en sí misma, una de las de más alta calidad del momento, con sistemas de control y seguridad centralizados e integrados.
\end{abstract}

SUMMARY

The functionallity is the main aspect of the urban area of the twin towers located at the end of the "Paseo de la Castellana" (Madrid).

With a tilting of $15^{\circ}$ over the vertical and crossing directions, such architectonic area is detached for its place and design of facilities and instalations.

The structural system is very complex due to the high technology applied for its construction, what made very difficult the ending of project.

The "Puerta de Europa" towers will be used for office rental and they are (due to the structural system and quality of construction materials used) one of the most important buildings due to not only to the quality of materials and design, but also due to their security and control centralized systems.

\section{Los orígenes}

Madrid comienza su expansión al norte, a lo largo del presente siglo, hacia lo que actualmente conocemos como la Plaza de Castilla.

Desde finales de los años veinte y primeros de los treinta, se realizan proyectos urbanísticos como los de Secundino Zuazo y Herman Hansen para, con el nombre de Avenida de la Libertad, prolongar la Avenida de la Fuente Castellana, o Paseo de la Castellana, como actualmente se la conoce, desde el hipódromo que se alzaba en lo que hoy es la Plaza de San Juan de la Cruz, hasta el lugar llamado "El Hotel del Negro", situación de la actual Plaza de Castilla.

Ésta es en realidad la tercera ampliación de la Castellana; la anterior había tenido lugar en el último tercio del siglo XIX y abarcó desde la Plaza de Emilio Castelar hasta el hipódromo, donde se construyó el actual edificio del Museo de Ciencias Naturales y la Escuela de Ingenieros Industriales.

El inicio real de esta tercera ampliación de Madrid hacia el norte tuvo lugar en 1932 con la demolición del hipódromo y el inicio de la construcción de los Nuevos Ministerios, obras que se vieron interrumpidas por la guerra civil.

Algún tiempo después del término de la contienda, a partir de 1941, se reanudan las obras siguiendo el "Plan Bidagor". Este plan, de acuerdo con los antiguos proyectos de Zuazo, contempla la apertura de "una autopista de entrada a Madrid" conectada por el norte con la carretera de Francia. Esta autopista, concebida como un eje totalmente rectilíneo, llevó a la incorporación, en 1948, al Ayuntamiento de Madrid de la Villa de Chamartín de la Rosa, a la que correspondían los terrenos objeto de la ampliación. 
Durante los años siguientes se produce la gran expansión de este área de Madrid. La construcción a finales de los cuarenta del estadio de fútbol de Chamartín, hoy Santiago Bernabeu, y de las viviendas para militares de los EE.UU. próximas a la que será la Plaza de Castilla, la ejecución del depósito del Canal de Isabel II en la propia plaza en 1950 y la construcción, más allá de la misma, a partir de 1955, de las viviendas para funcionarios de la EMT, conocidas popularmente como "los nichos", supusieron el despegue definitivo de una zona que, entre los años sesenta y los ochenta, vio la aparición del monumento a Calvo Sotelo, la SEAT, la Ciudad Sanitaria de La Paz, edifícios de periódicos, bancos, viviendas, la CiudadDeportiva del Real Madrid, AZCA, los Juzgados de la Plaza de Castilla, la estación de RENFE de Chamartín, etc., lo que la convirtieron en una de las zonas con mayor pujanza del Madrid moderno, siendo la Plaza de Castilla, como nudo de comunicaciones, uno de sus puntos focales.

Desde los primeros proyectos urbanísticos de Zuazo, a principios de siglo, ya se refleja la idea de la construcción de dos rascacielos en el extremo de la ampliación de la Castellana. Estos rascacielos, a semejanza de la idea de Le Corbusier de 1929 para la Porte Maillot de París, conformarían una puerta monumental de entrada a la ciudad desde el norte.

Muy diversos proyectos se han propuesto a lo largo de los años para la edifícación de estas parcelas como el del arquitecto Bonet, que en los años sesenta, proponía dos edificios singulares de cincuenta plantas cada uno. Fue a raíz de los convenios urbanísticos surgidos a partir de las permutas de terrenos, necesarias para la construcción de la estación de Chamartín, cuando se empezó a gestar la actual configuración de parcelas, que tuvo su reflejo final en las prescripciones que, para el desarrollo de esta zona, incluía el Plan General de Madrid de 1985.

Los valores fijados para la edificabilidad corresponden con los acordados en el convenio del año 1984 entre el Ayuntamiento de Madridy Urbanor S.A., por aquel entonces propietaria de los únicos terrenos privados afectados por la remodelación. Asimismo, en este Plan General se recogía la necesidad de una reordenación de los viales de lazona, utilizando terrenos que serían cedidos por Urbanor al Ayuntamiento y la construcción de un intercambiador de transporte ${ }^{(1)}$

Con posterioridad, y de acuerdo con lo recogido en el convenio urbanístico del año 1984, se encargó a los arquitectos Pedro Sentieri Cardillo y Javier Sebastián Nuño, la redacción del correspondiente Estudio de Detalle que desarrollara definitivamente las prescripciones del Plan General. Este Estudio de Detalle E.D. 5.2. aprobado

\footnotetext{
(a) Artículo publicado en el $n^{\circ} 436$ de esta misma Revista
}

provisionalmente por el Ayuntamiento de Madrid en 1987 y definitivamente el 4/VII/1988, define finalmente todas las actuaciones urbanísticas e incluye, por primera vez, a petición de los técnicos municipales, la condición de construcción de un paso de vehículos bajo la plaza que descongestionaría el tráfico rodado, tanto el existente como el inducido por la construcción de las edificaciones.

A partir de este momento empieza ya el proceso final de tramitación que culminaría con la aprobación, en noviembre de 1989, de los proyectos de urbanización general y de parcelas y la presentación de los proyectos básicos de edificación en febrero del año siguiente. En otoño de ese mismo año se concedieron las oportunas licencias de obra, dando comienzo las mismas.

\section{El diseño}

No fueron sencillas, como se ha visto, las decisiones relativas a los diseños, tanto urbanísticos como arquitectónicos. Finalmente, y provocando una importante polémica dentro del mundo de la arquitectura española, se decidió recurrir al equipo del arquitecto neoyorquino John Burgee para la realización del diseñofinal del conjunto.

El equipo del estudio de arquitectura se puso manos a la obra y después de una visita a Madrid de John Burgee, surgió la propuesta de diseño de las torres inclinadas. Una iniciativa singular, novedosa y arriesgada, no en el aspecto de seguridad sino en los importantes problemas, no resueltos, que la construcción de unas torres inclinadas acarrearía.

$\mathrm{El}$ ¿por qué construir unas torres inclinadas? es la gran pregunta que rodea a este proyecto. Aunque algunos arquitectos, como el estadounidense Gunnar Birkets, justifican la inclinación en sí misma como "la liberación del edificio de la vertical para dejar atrás el papel tradicional de la adaptación funcional, la complacencia visual y las actitudes generales de las estructuras de gran altura", en este caso, la justificación del diseño inclinado se encuentra en el entorno y en la forma en que debería desarrollarse el proyecto.

En concreto, se pensaba en dos torres con "huellas" ampliamente separadas. La separación era necesaria para evitar tres estaciones de metro, los pasos inferiores para peatones correspondientes y los derechos de acceso de una calle no edificada. Las alturas y dimensiones en planta de las torres estaban tan separadas que no era posible que formaran un conjunto ni que definieran los bordes del Paseo de la Castellana. En lugar de ello amenazaban con dar el aspecto de una simple repetición, lo que ocurre con tanta frecuencia en las casos de bloques de casas. Se solucionó el problema inclinando las torres mutuamente. Se estableció con ello una relación inmediata entre las dos formando una gran puerta. Puesto que las torres están 
situadas en una arteria de intenso tráfico, la imagen de la puerta parece muy adecuada.

John Burgee hizo suya y desarrolló completamente la idea inicial de Zuazo y la convirtió en los edificios inclinados que hoy conocemos por Puerta de Europa, con la intención de que se convirtieran en el futuro, como así ha sido, en un símbolo del Madrid de finales del siglo XX.

Se diseñan, pues, dos torres inclinadas simétricas con respecto al eje del Paseo de la Castellana, de salida de la plaza hacia el norte. Aunque, dado que la Castellana quiebra ligeramente su alineación a su paso por la plaza, se produce un ligero descentramiento de las torres cuando son vistas desde el lado sur de la misma; la vista de entrada a Madrid desde el norte corresponde a la idea original de puerta.

La geometría de las torres corresponde a un paralelepípedo de bases horizontales cuadradas de $35 \mathrm{~m}$ de lado, $115 \mathrm{~m}$ de altura y dos caras inclinadas $14,3^{\circ}$. Esto se traduce en que el desplazamiento total de la coronación con respecto a la base, debido a la inclinación, es prácticamente de $30 \mathrm{~m}$ lo que produce que sólo una estrecha banda de apenas $5 \mathrm{~m}$ de ancho se solape de base a cubierta, lo suficiente para la disposición de los últimos ascensores y para la vertical remarcada de la fachada.

En el volumen interior se desarrolla el programa completo de edificabilidad propuesto por el planeamiento urbanístico. Se plasma en total en cada torre en tres plantas de sótano, planta baja, una entreplanta técnica, veinticuatro plantas útiles de oficinas y los niveles de instalaciones y cubierta superiores que se coronan con el helipuerto.

El diseño original de John Burgee fue completado en España inicialmente por el estudio del arquitecto Pedro Sentieri y, en fase posterior, por los también arquitectos Tomás Domínguez del Castillo y Juan Carlos Martín Baranda, que han desarrollado la arquitectura interior de los edificios.

Para conocer los aspectos de diseño más relevantes, se podría pensar en un recorrido ideal por el edificio que comenzaría en los sótanos, en los que se distinguen claramente dos zonas: el cuadrado que corresponde a la huella vertical de la base de la torre y la parte exterior a él, hasta completar la superficie de la parcela.

En la parte interior de los sótanos, aparte de las comunicaciones verticales (escaleras y ascensores) propios de los sótanos, se ubican las dependencias de servicio comunes, distribuidas en el primer sótano, la sala de control central y seguridad del edificio, el centro de correos y mensajería, la central frigorífica y las centralizaciones de telefonía y contadores eléctricos. En el segundo sótano se encuentran todos los aseos y vestuarios del personal de servicio de mantenimiento, así como los necesarios almacenes diversos de la torre. En el tercer sótano, ya a nivel de solera, se hallan los equipos hidráulicos de fontanería y contraincendios, los aljibes, extractores de planta y salas en reserva para almacenes o usos varios.

En la zona exterior de los sótanos se desarrollan los aparcamientos exigidos por la normativa municipal, encontrándose también los centros de transformación de energía eléctrica, acometidas generales, etc.

La planta baja es el nivel de la entrada principal al edificio. En el exterior se constituye la gran plaza que conferirá al conjunto de las dos torres, con su espacio intermedio, el carácter de gran espacio urbano peatonal que la Plaza de Castilla demandaba desde hace mucho tiempo. Las rampas de acceso al edificio conducen, a través de las puertas giratorias, hastael interior de latorre donde el impresionante vestíbulo de entrada, en mármoles y granitos del país, da paso al área de ascensores, punto desde el que se puede uno dirigir a cualquiera de las plantas útiles de oficinas.

A espaldas de los mostradores de control y detrás de la gran mampara de madera, existen dos locales comerciales para la instalación de negocios relacionados con el uso de las plantas (oficinas bancarias, etc.). Estos locales disponen de una entreplanta construida dentro de la altura del vestíbulo $(7 \mathrm{~m})$. Al nivel de esta entreplanta, denominada como planta Mezzanine, en el interior del núcleo de ascensores, se encuentran una serie de cuartos técnicos y sus maquinarias.

Desde el vestíbulo principal se puede elegir entre ocho ascensores para el acceso a las plantas. Cuatro de ellos constituyen la batería baja que da acceso a las plantas primera a decimotercera, ambas inclusive. Los otros cuatro permiten el acceso directo desde planta baja a la planta trece y siguientes hasta la veinticuatro. El motivo de esta interrupción de la primera batería de ascensores es que la inclinación de la fachada trasera hace que ésta llegue a interceptar su vertical, impidiendo que progrese por encima de la mencionada planta trece. Los ascensores de la batería alta, en el recorrido directo hasta esa planta, disponen solamente de salidas de emergencia a los vestíbulos de servicio.

Todos los vestíbulos principales de ascensores de las plantas, aunque con diferentes dimensiones en algunos casos, tienen diseños similares y acabados en mármoles pulidos dispuestos en piezas de gran tamaño. Los solados combinan granitos y mármoles con diferentes texturas en su acabado.

Los ocho ascensores tienen acabados de lujo en acero inoxidable, mármol y madera de palosanto y están pensados sólo para el transporte de personas. Pero, comoen todo edificio de oficinas se necesita acceder a las plantas con 

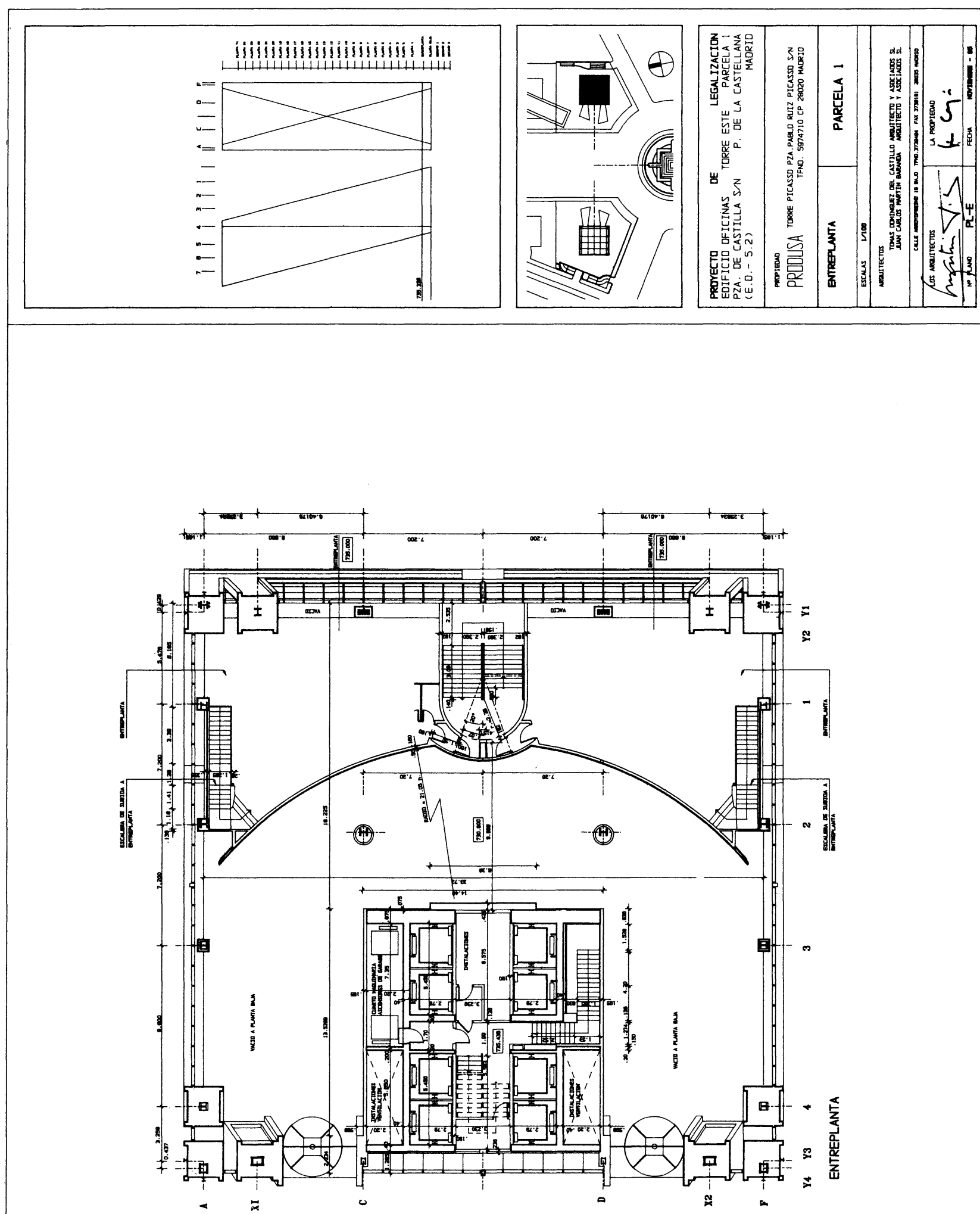

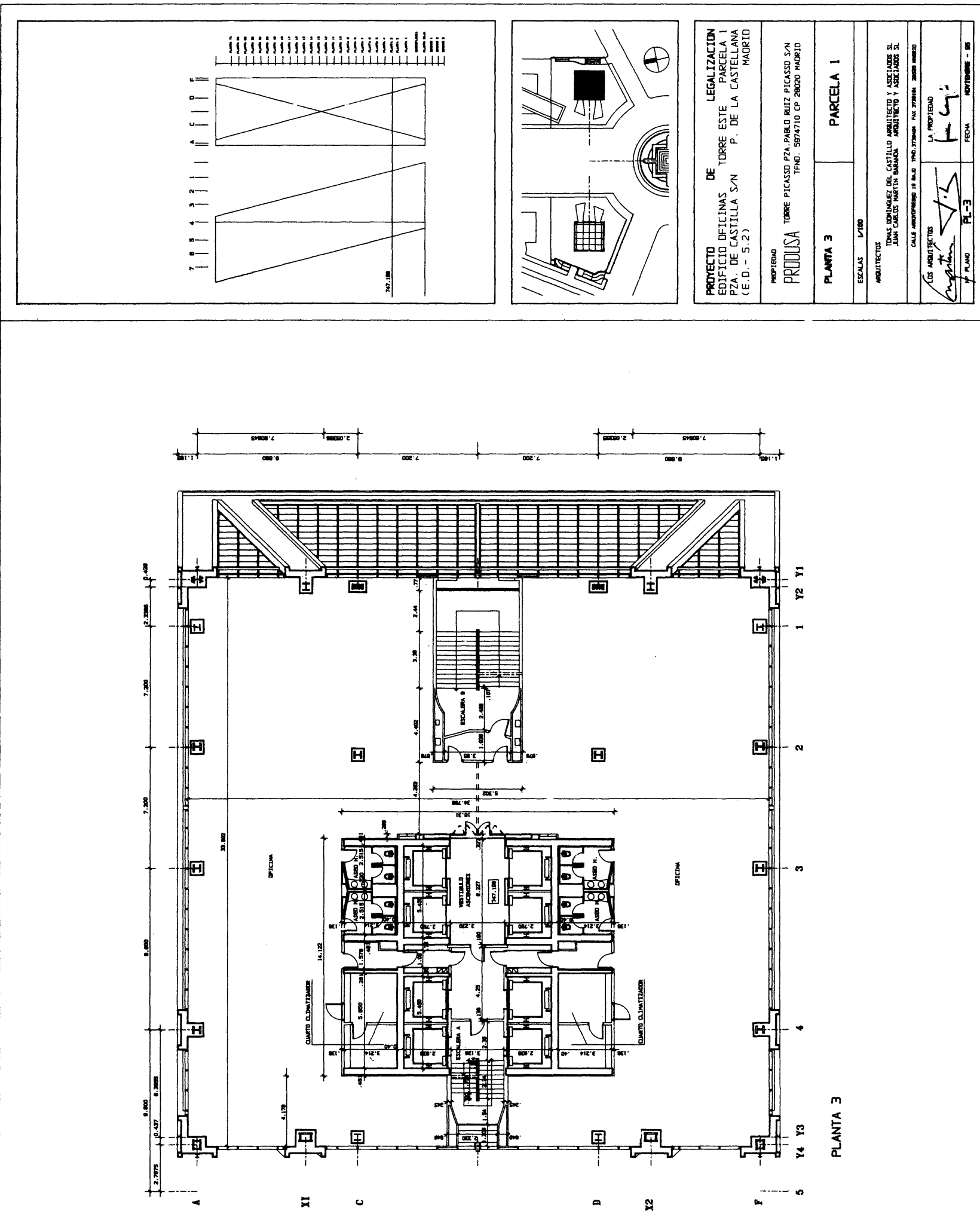

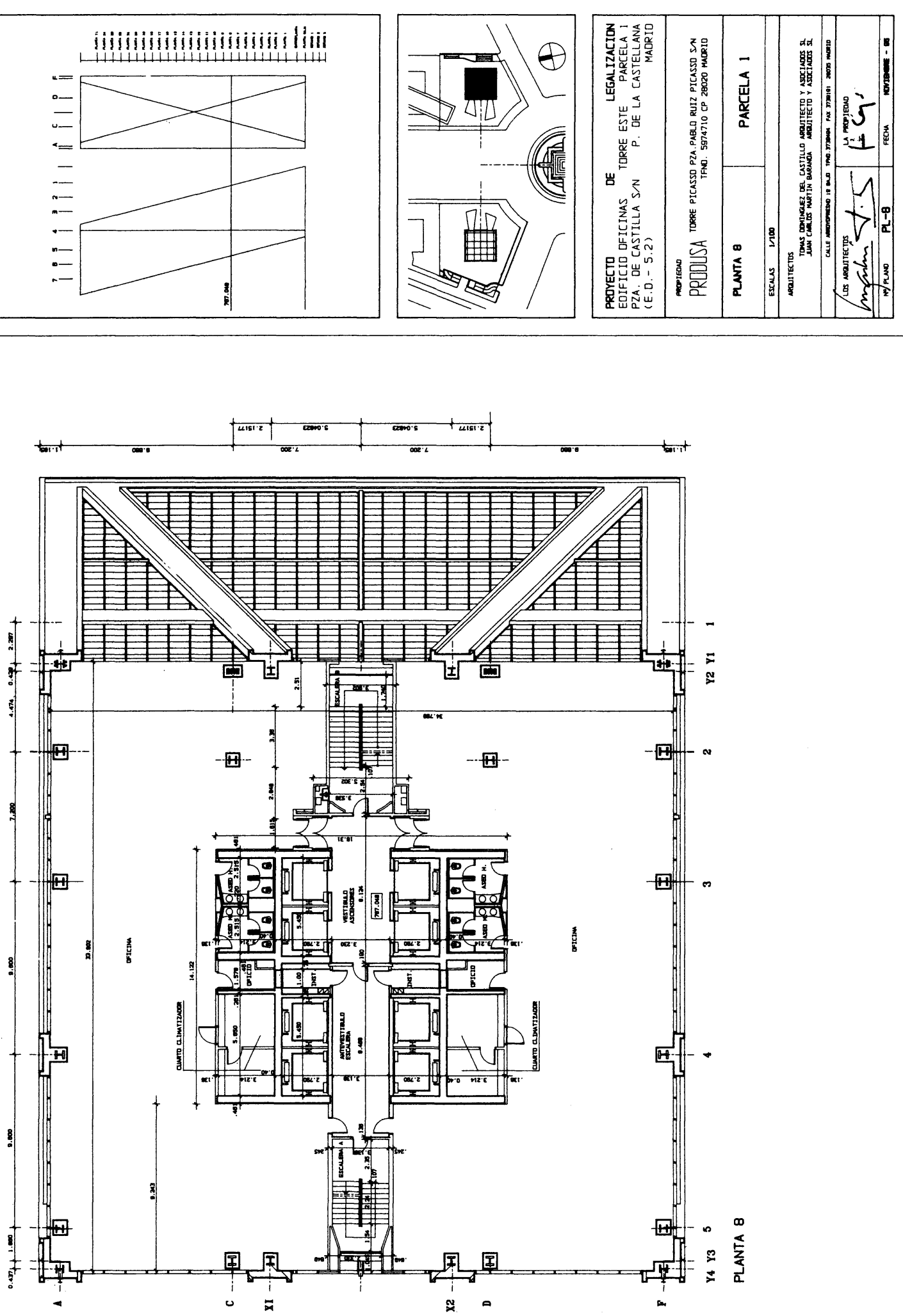


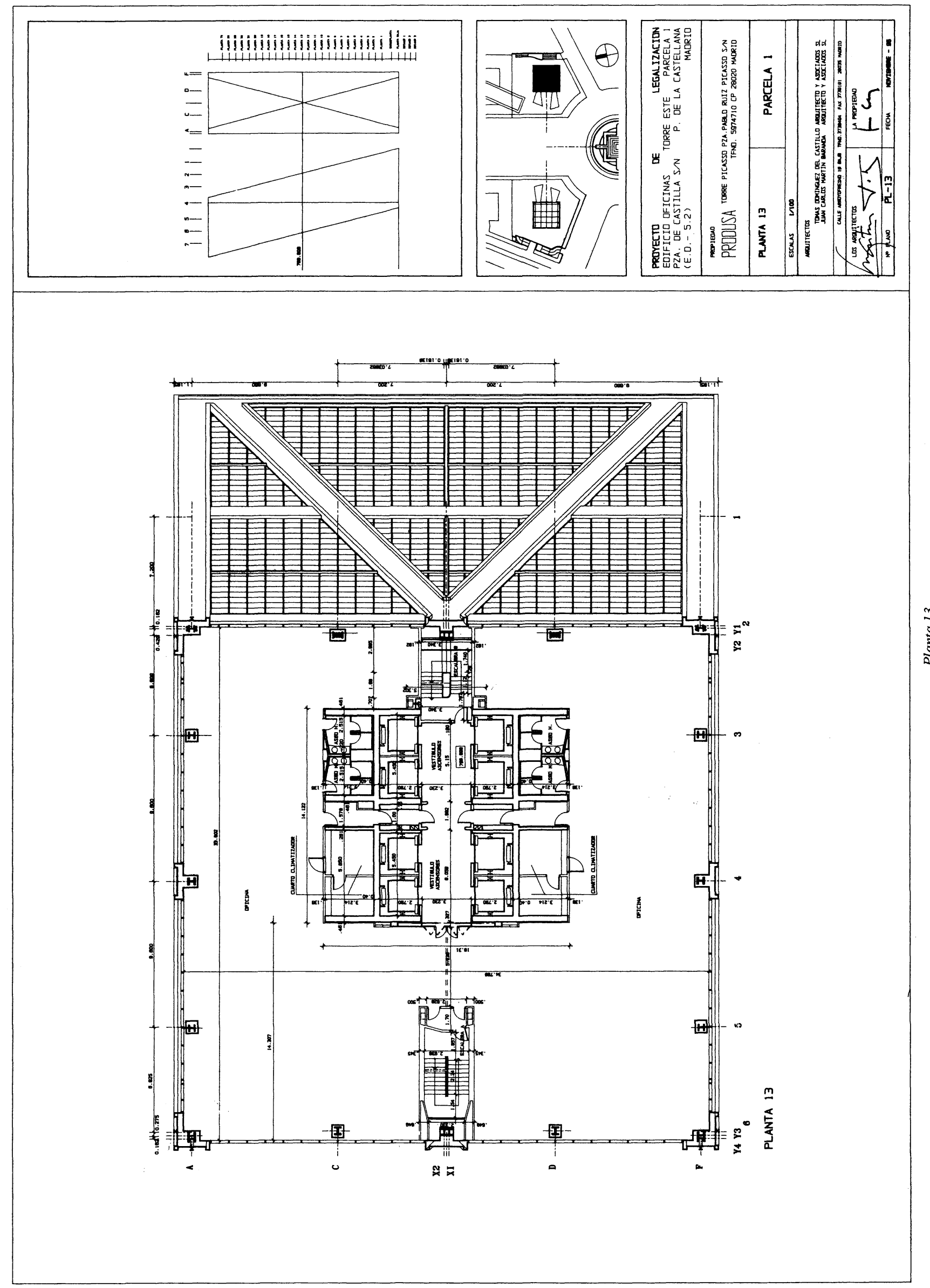




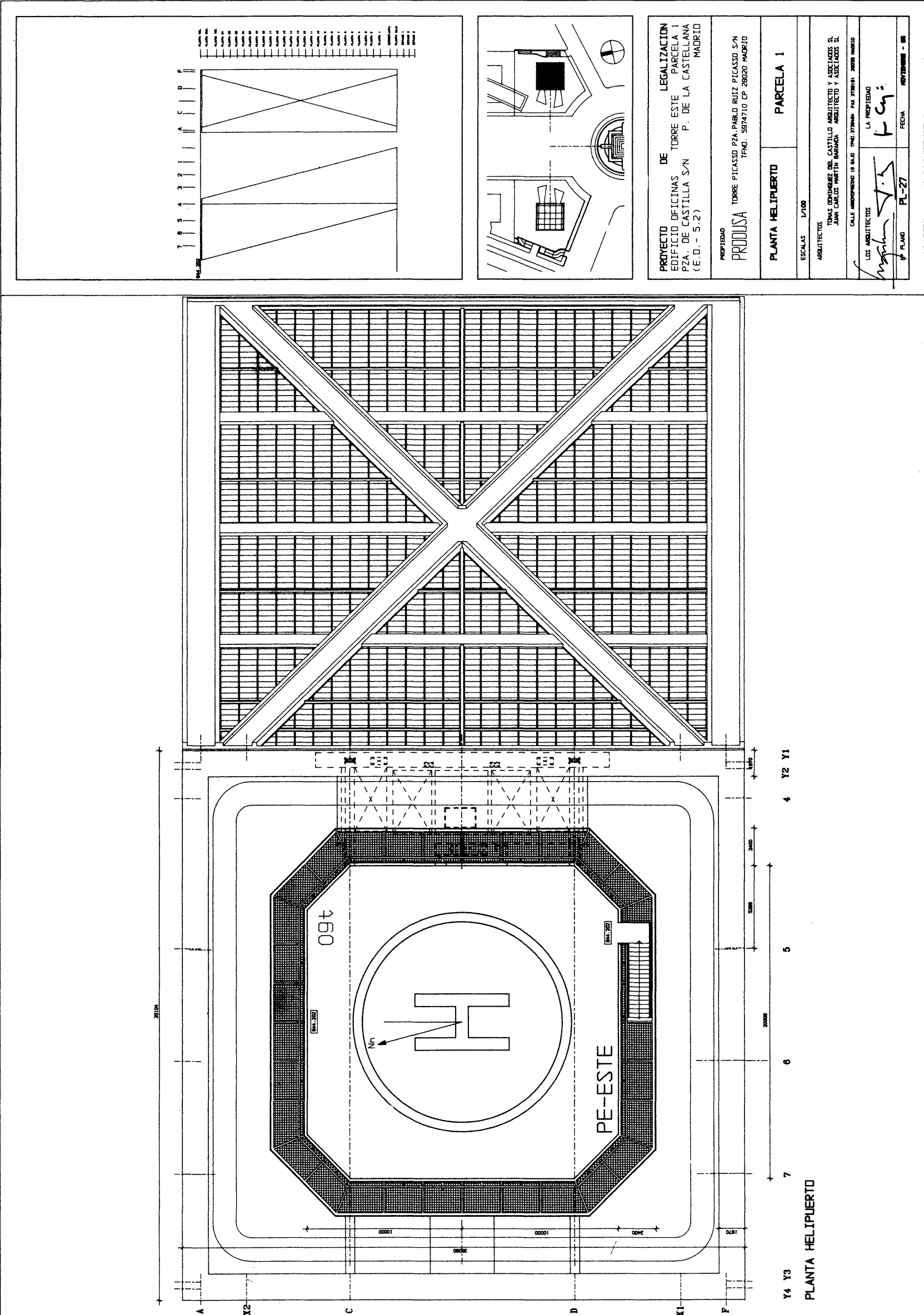



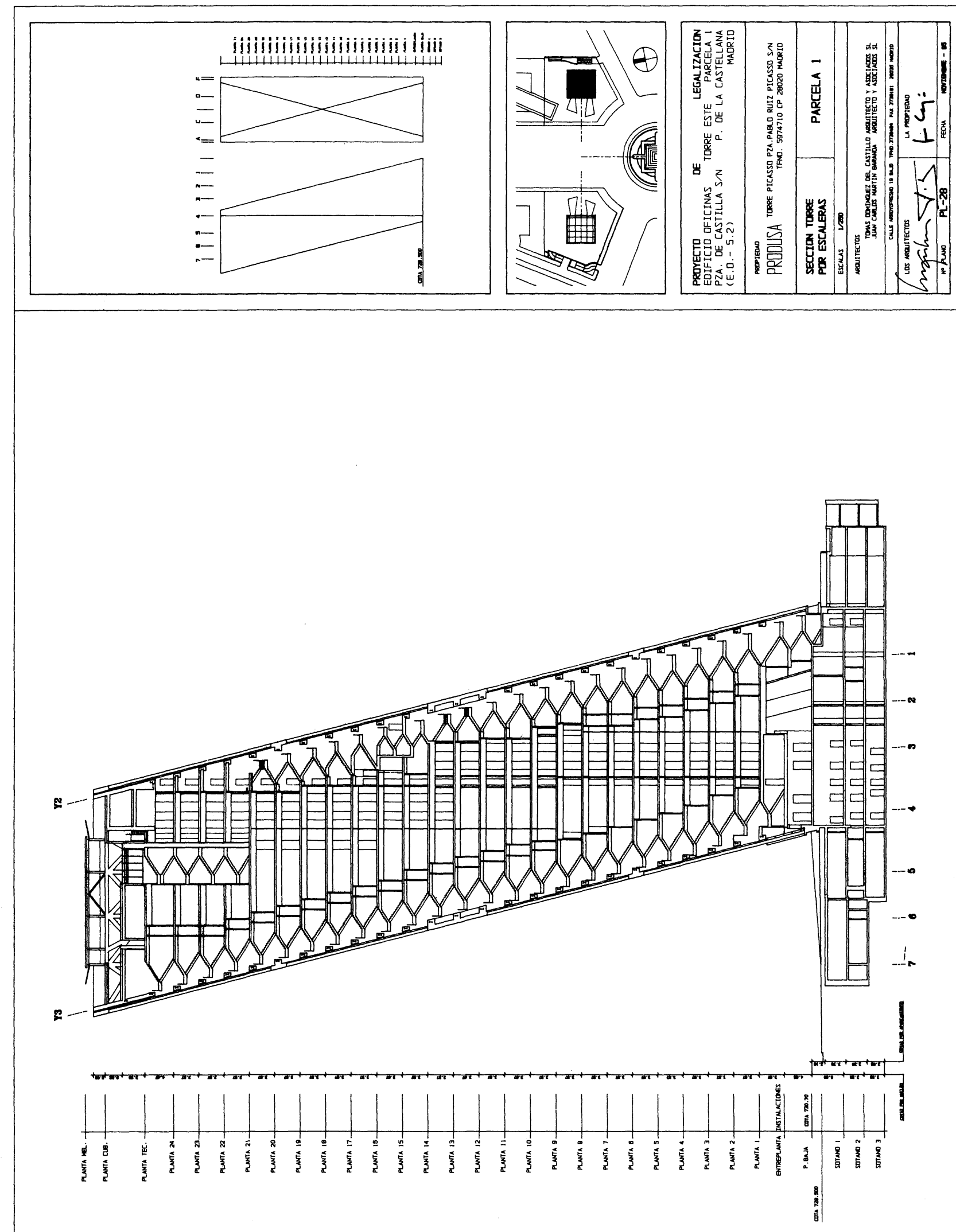

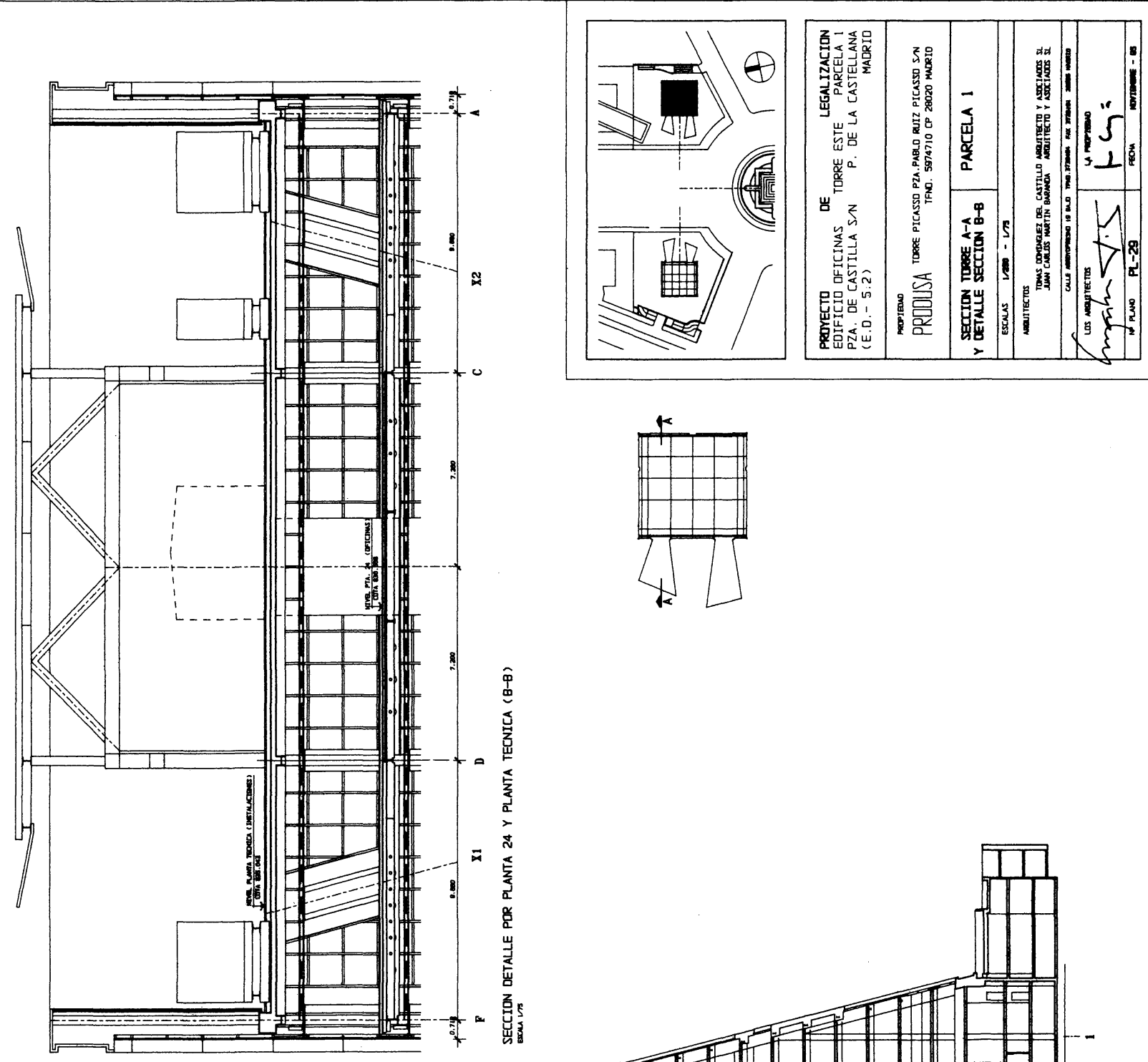
material, muebles, etc., que pueden dañar los acabados, para evitarlo, sin la pérdida de capacidad que supone ocupar con un montacargas uno de los escasos huecos de ascensor, se ha recurrido a los de doble cabina. Estos ascensores disponen de una cabina superior decorada como la del resto de ascensores y que es la que normalmente está en uso y, por debajo de ella, cuelga una segunda con una decoración exclusivamente funcional que, conmutable desde la sala de control del edificio, puede, a solicitud, ser la que entre en uso como montacargas de acceso a las plantas.

Las plantas de oficina son, cada una de ellas, distinta de las demás a causa de la inclinación del edifício, que hace que los límites de fachada se vayan desplazando respecto al

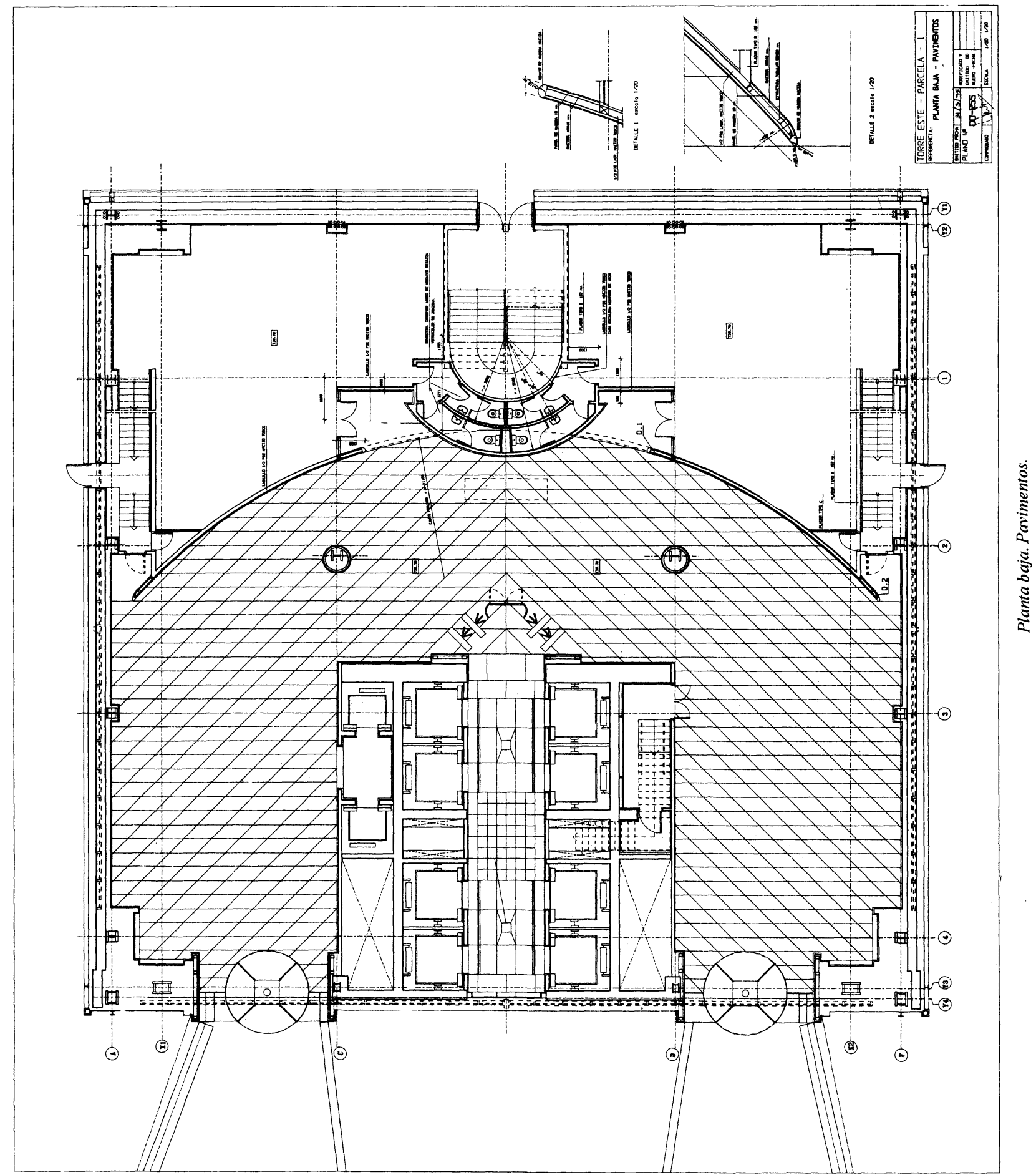


núcleo central de ascensores, cambiando por completo la disposición de planta. A partir de la dieciséis, al reducirse la superficie ocupada por la vertical de ascensores (la batería baja llega hasta la planta trece, pero la ocupación por salas de máquinas, etc. llega hasta la planta dieciséis), ésta se recupera para superficie útil de oficinas. Las oficinas están pensadas para su utilización, bien en planta completa o bien divididas en mitades, razón por la cual en cada planta están duplicados los bloques de aseos, cuadros eléctricos, climatizadores, etc.

Las plantas se dejan diáfanas para que cada inquilino pueda realizar la distribución y compartimentación que desee. Como solados se han dispuesto falsos suelos técnicos para la realización de distribución de instalaciones de cualquier sistema. Los techos son también de placa registrable e incorporan las luminarias-difusor de aire acondicionado, los equipos de megafonía, detectores de incendios, etc. Todo ello confiere una flexibilidad de uso extraordinaria a los locales de oficinas, muy importante para el inquilino que no desea obstáculos para el diseño de su distribución.

Todas las oficinas disponen de tres salidas: una al vestíbulo de ascensores, que serála salida normal de funcionamiento, y dos a las escaleras de emergencia que recorren las

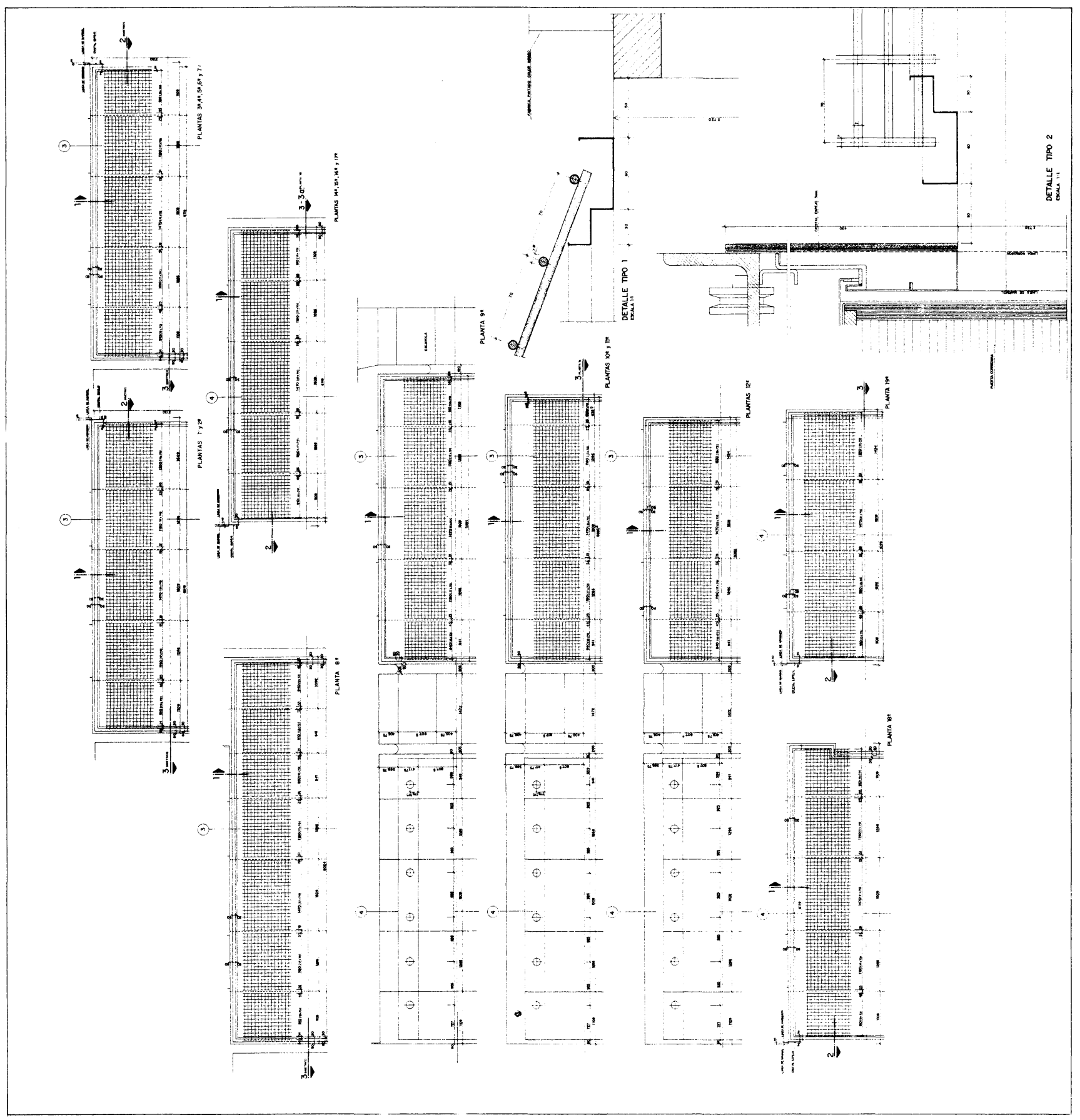


fachadas inclinadas de las torres. Estas escaleras de emergencia van a desembocar, una al vestíbulo principal en planta baja y la otra directamente a la plaza, por la parte trasera del edificio.

Para la comodidad y seguridad de los ocupantes se han diseñado las instalaciones del edificio con las más modernas tecnologías y los más avanzados sistemas de control y seguridad.

Las instalaciones eléctricas, partiendo de la central de transformación y con los elementos de mando y seguridad preceptivos, llegan hasta las dos centralizaciones de contadores (una en el sótano primero y otra en las salas técnicas de la planta veinticinco), donde se dispone de contador independiente para cada media planta y desde donde discurren las acometidas propias hasta los cuadros de protección y maniobra de cada local. Para casos de emergencia se han instalado en cubierta dos grupos electrógenos que dan servicio a las instalaciones fundamentales.

Todos los locales disponen de acometidas de telefonía, voz y datos, previstos para la utilización de equipos ofimáticos

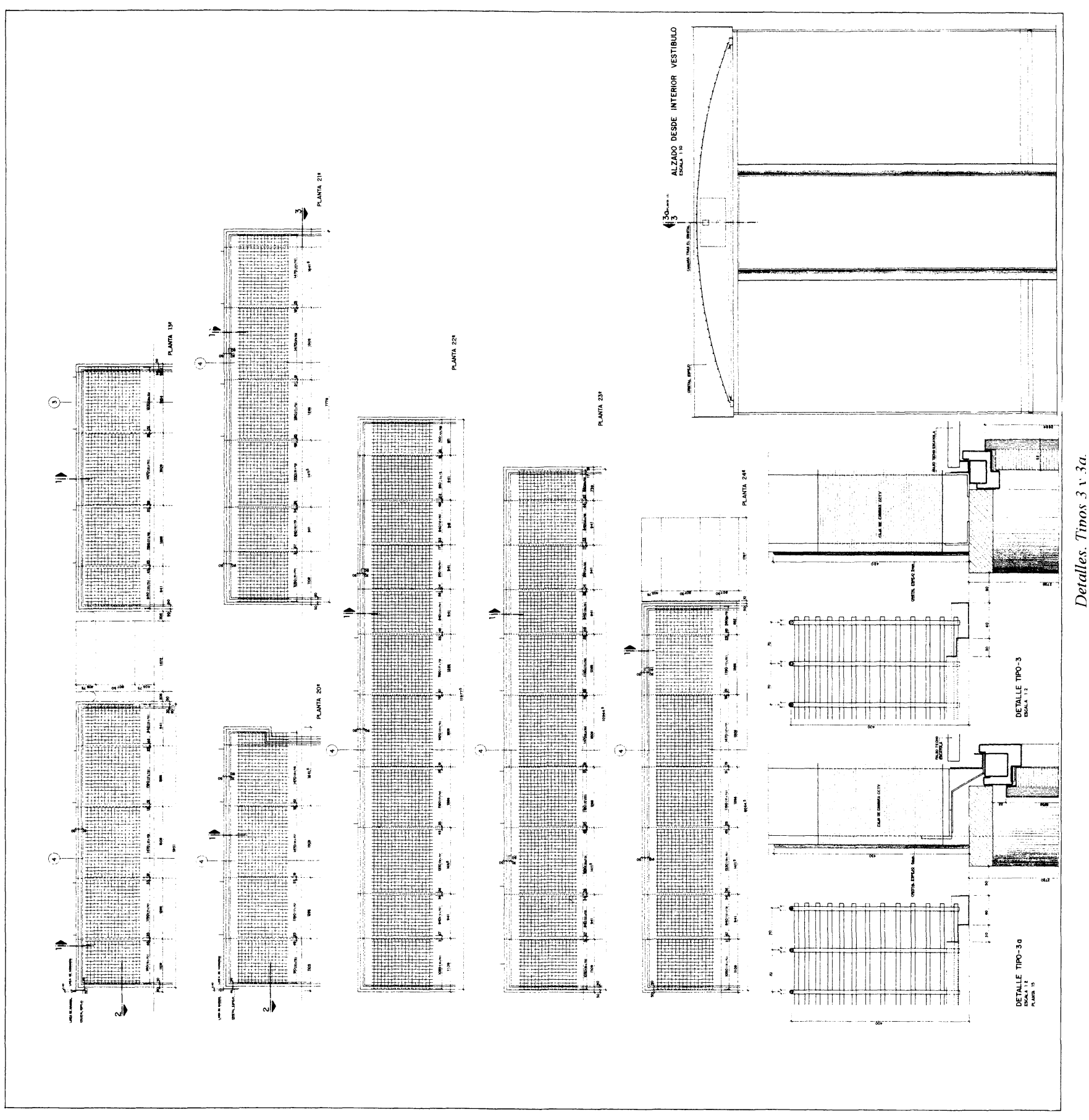


$\frac{19}{996}$

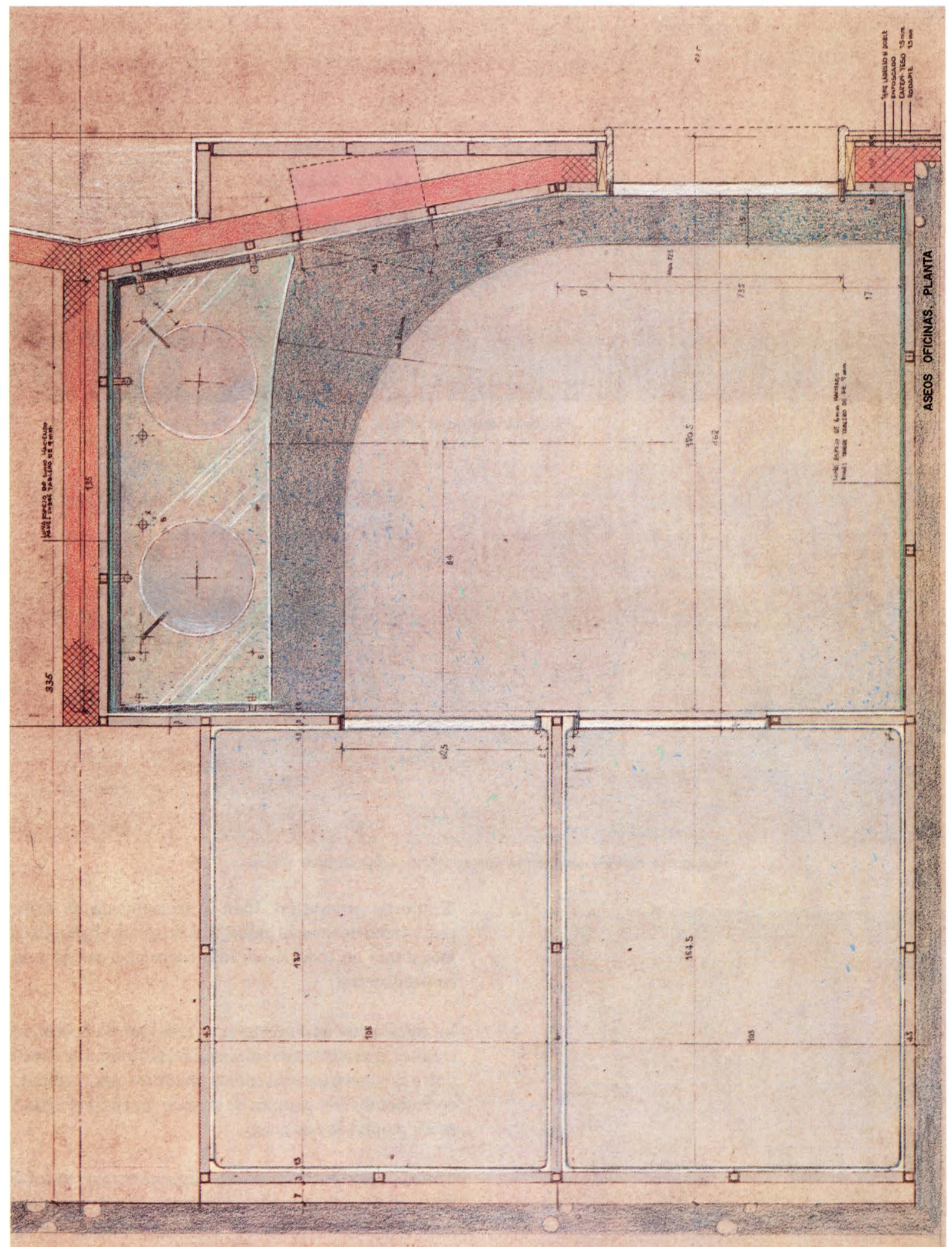

(c) Consejo Superior de Investigaciones Científicas

Licencia Creative Commons 3.0 España (by-nc)

http://informesdelaconstruccion.revistas.csic.es 


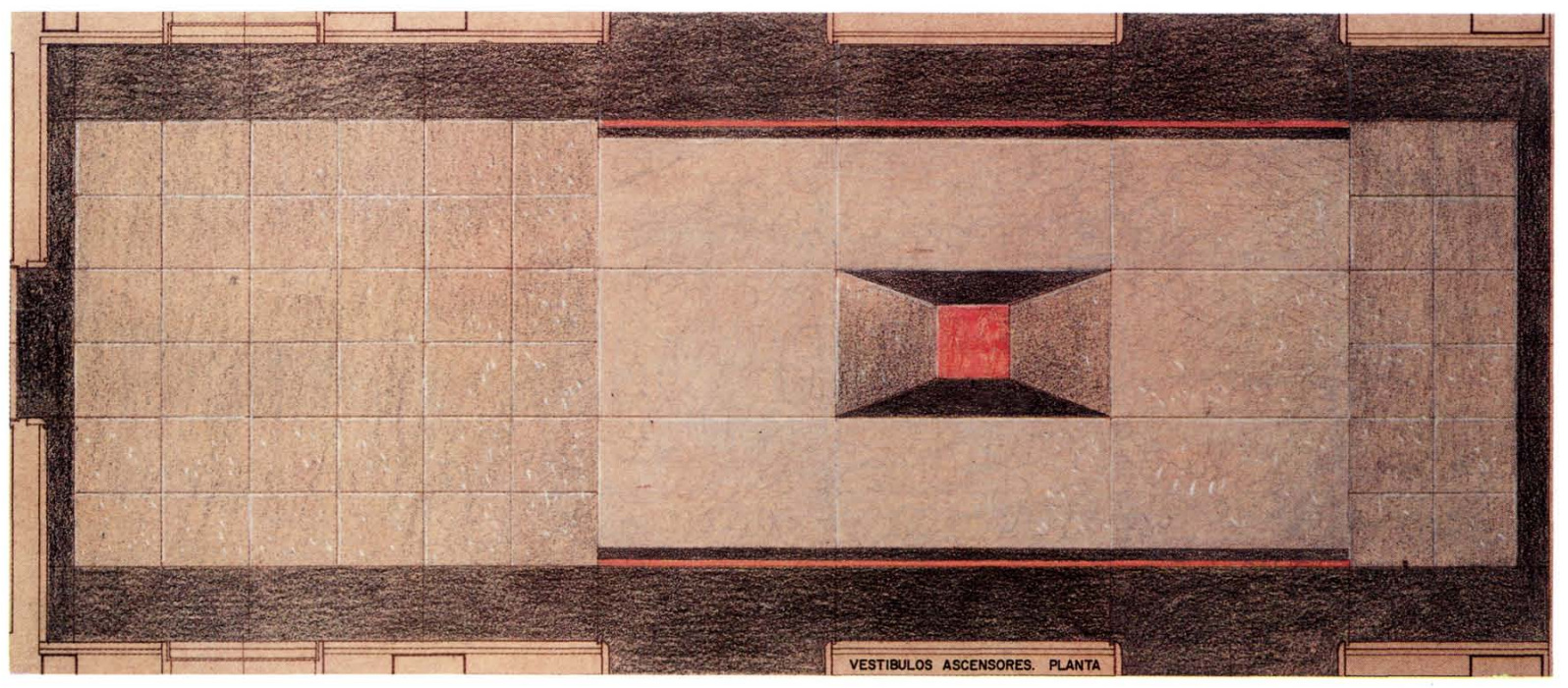

Vestibulos ascensores. Planta.

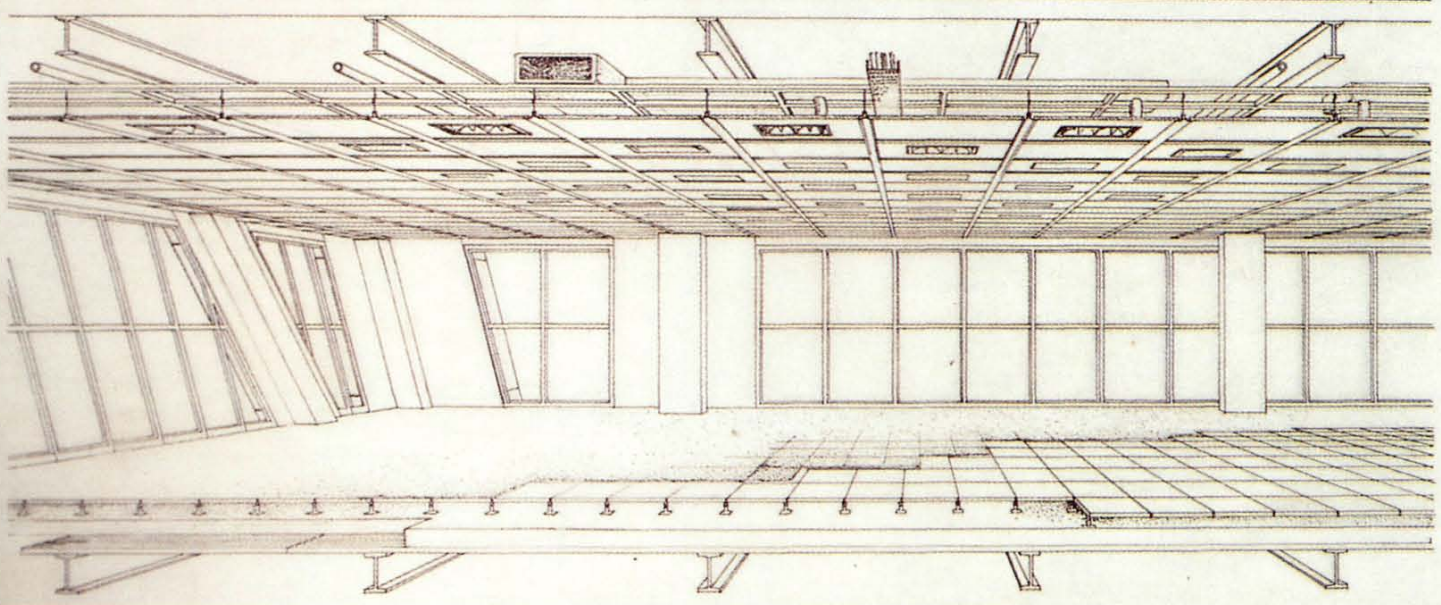

Perspectiva. Sección constructiva tipo, con falso suelo y techo de oficinas.

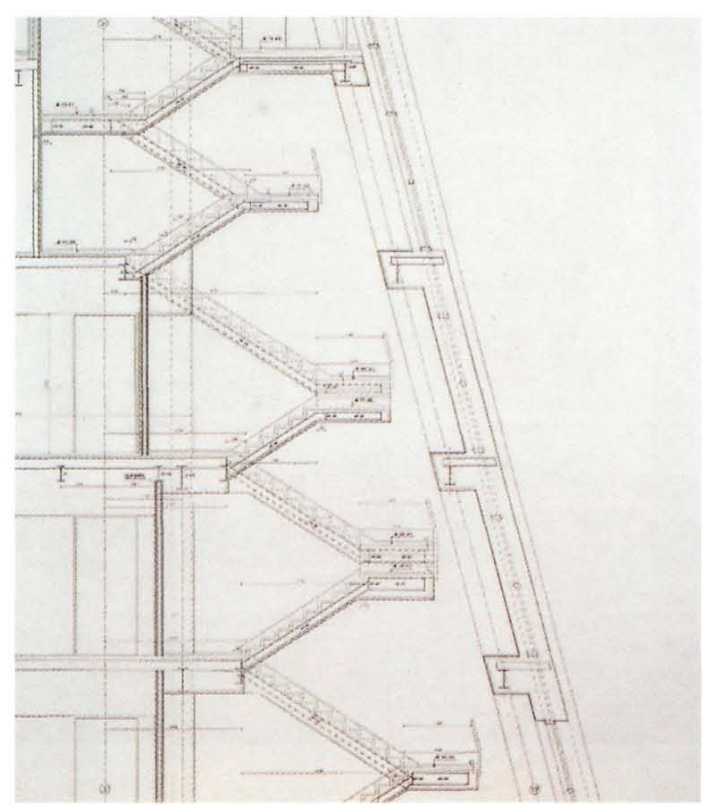

Tiro de escalera.

(c) Consejo Superior de Investigaciones Científicas Licencia Creative Commons 3.0 España (by-nc) de última generación. Para la transmisión de avisos y posibilidad de música ambiental existe una instalación de megafonía en todo el edifício conectada con la sala de control central.

La instalación de fontanería se abastece de la acometida exterior que vierte a dos aljibes, unopara agua de consumo y otro exclusivo para incendios, desde los que, mediante los correspondientes equipos de presión, se eleva el agua hasta los puntos de consumo.

La instalación contraincendios dispone de una red de bocas de incendio, columna seca, hidrantes, una red de rociadores automáticos y extintores manuales. Se dispone de un sistema de detección y alarma mediante detectores iónicos de humos y termovelocímetros, así como sistemas manuales, todo ello conectado con la sala de control central.

El sistema de climatización es centralizado. El tratamiento de las plantas es del tipo todo aire, mediante dos climatizadores por planta, que se abastecen de agua caliente http://informesdelaconstruccion.revistas.csic.es 
y fría de una central térmica con tres calderas situadas en cubierta, con una potencia de 540.000 kilocalorías por hora cada una, y una central frigorífica con tres grupos enfriadores de 910.000 frigorías/hora, con el agua para condensación proveniente de dos torres de refrigeración situadas en cubierta.

Todas estas instalaciones se complementan con sistemas de protección contra intrusos, pararrayos, red de tierras, etc., sistemas destinados a la seguridad y bienestar de los ocupantes del edificio.

Continuando el recorrido ascendente por la torre, se llega a la planta veinticinco o planta técnica donde, como se ha visto, se encuentran una buena parte de los equipos principales de las instalaciones del edificio (grupos electrógenos, calderas, torres de refrigeración, etc.), así como la segunda centralización de contadores eléctricos. El entramado metálico que cubre esta planta sirve como soporte del equipo de limpieza de ventanas.

Como otros muchos elementos de estas torres, el equipo de limpieza de ventanas no podía ser, ni mucho menos, convencional. La necesidad de acceder a la limpieza de planos inclinados obligó al diseño de un sistema especial totalmente "a medida". Dicho sistema consiste en una góndola, similar a la de cualquier otro edificio, pero que no cuelga directamente desde cubierta, sino que se desliza por una gran barra metálica de $35 \mathrm{~m}$ de longitud. Esta barra, que cuelga mediante cables de la cubierta, vafijada mediante un sistema de rodillos a unas guías que recorren las esquinas de las fachadas, de forma que queda obligada a seguir la inclinación del plano.

Por encima de este nivel de cubierta está el helipuerto que corona cada una de las torres. Estos helipuertos, de $20 \times 20 \mathrm{~m}$, están previstos para aparatos de hasta $4.000 \mathrm{~kg}$ de peso y, catalogados como de uso privado, pueden ser usados para la evacuación de personas en casos de emergencia o seguridad.

La fachada de las torres, aunque originalmente estaba prevista en vidrio y granito rosa de Porriño (material que enamoró a John Burgee en su visita a España), propuesta que por razones constructivas de exceso de peso se desechó, es un diseño que mezcla el vidrio, el aluminio y el acero inoxidable que conforma las grandes bandas brillantes características de la misma, incorpora los elementos de guía para el sistema de limpieza de ventanas y está concebido para garantizar los niveles óptimos de aislamiento térmico y acústico.

Exteriormente, la urbanización de los grandes espacios creados en torno a las dos torres se une, según palabras de los arquitectos Tomás Domínguez y Juan Carlos Martín, en una "gran alfombra rectangular"que, basada en los adoquinados de granito y la jardinería, configuran la gran plaza que se pretende.

(c) Consejo Superior de Investigaciones Científicas

Licencia Creative Commons 3.0 España (by-nc)
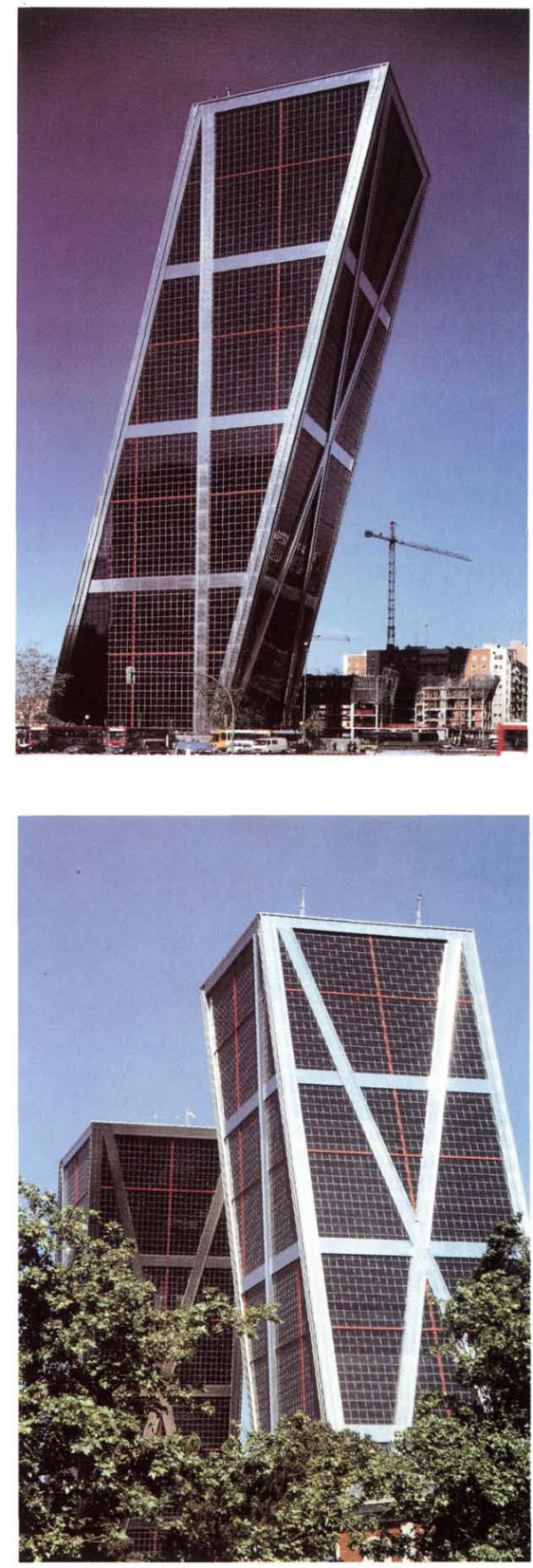

Las torres, desde distintos ángulos.

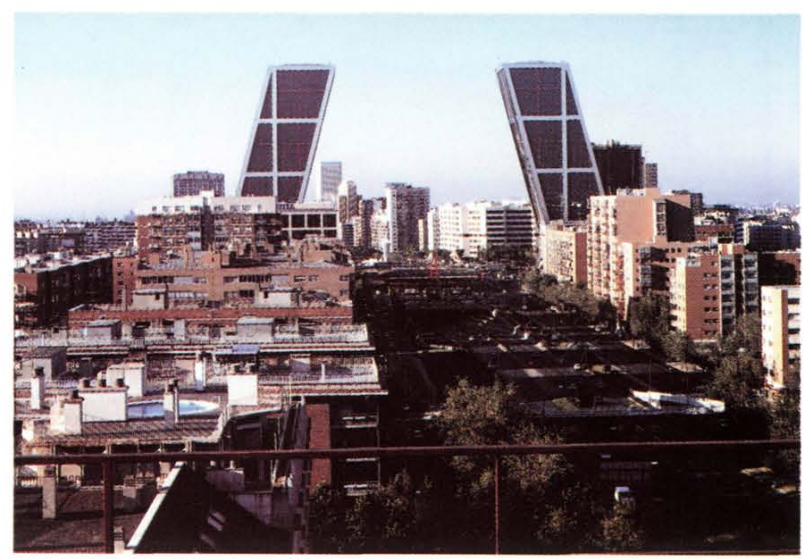

Panorámica de las torres.

http://informesdelaconstruccion.revistas.csic.es 


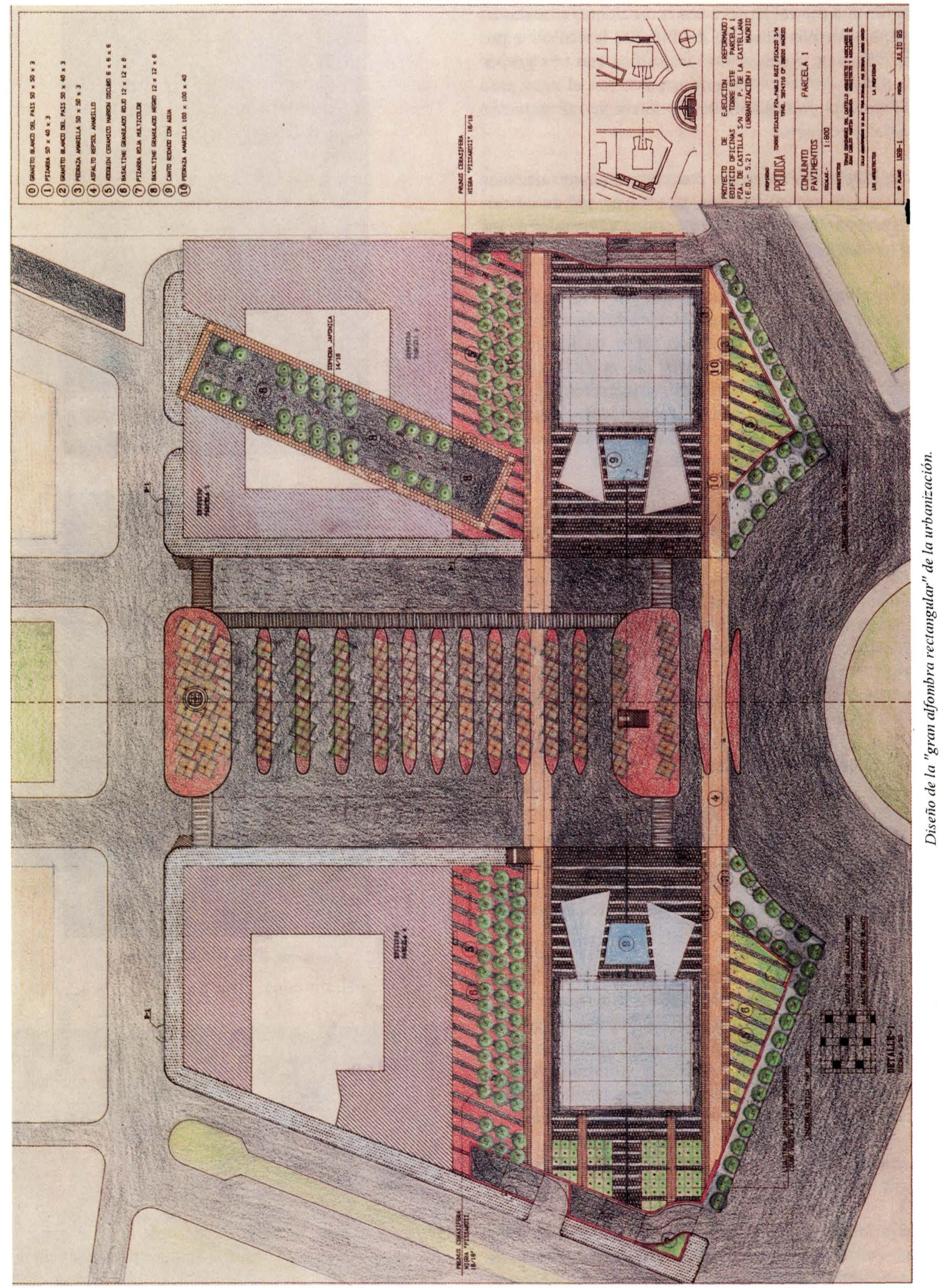


Para completar estagran plaza, además de las torres y como elementos de diseño y utilidad, se incorporan los pasos subterráneos, el intercambiador de transporte y la fuente central, algunos de los cuales son fruto de convenios entre la propiedad de las torres y el Ayuntamiento, y han sido cedidos a éste para el disfrute de los madrileños.

Queda con todo ello completo el dibujo final de una plaza que se incorpora de pleno derecho a la lista de los símbolos del Madrid del año 2000

\section{La estructura}

¿Cómo debe ser la estructura de estos edificios?, ¿qué elementos se deben disponer para asegurar su estabilidad?, ¿cuál será su comportamiento durante la vida útil del edificio?. Éstas e infinidad de otras cuestiones se plantearon al principio legos y expertos, que ponían en duda la viabilidad del proyecto.

Para obtener respuestas se recurrió a una de las oficinas de más prestigio a nivel mundial: Leslie E. Robertson Associates (LERA). Esta oficina, dedicada prácticamente en exclusiva al diseño estructural de edificios singulares, posee un "curriculum" absolutamente envidiable; baste sólo mencionar algunas referencias: las "Torres Gemelas" de Nueva York, el Banco de China de Hong Kong o, la más modesta y cercana, Torre Picasso de Madrid. El proyecto, realizado en EE.UU., incluía el diseñoy dimensionamiento estructural, desarrollándose el de ejecución final en Madrid a través de la oficina técnica que la Unión Temporal de Empresas, adjudicataria de la obra principal, creó en obra realizando su definición final con un total superior a los siete mil planos.

Para explicar el funcionamiento de la estructura y definir la misión de cada uno de los elementos constructivos que componen las torres, se puede seguir el "camino" imaginario

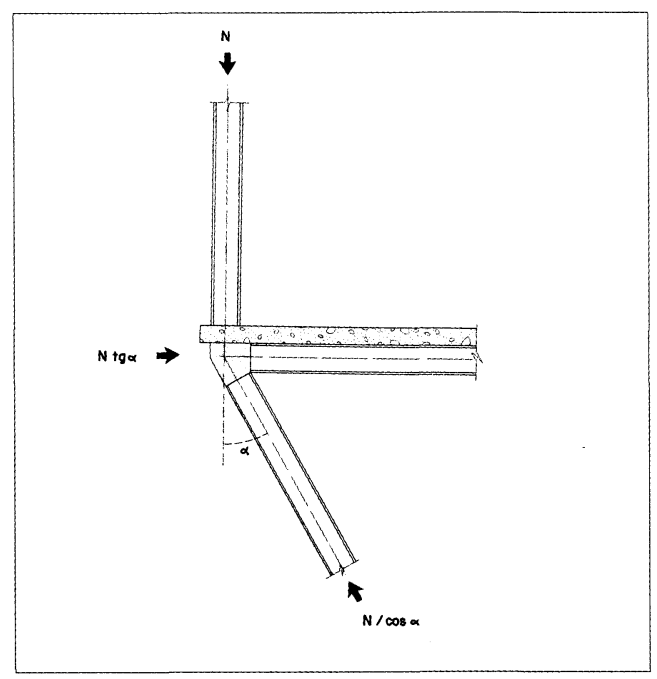

Esquema de transmisión de cargas.

(c) Consejo Superior de Investigaciones Científicas Licencia Creative Commons 3.0 España (by-nc) que seguiría un peso colocado en cualquier punto del edificio hasta el terreno en que se apoyan las torres.

Los pisos o forjados de las plantas trabajan como los de cualquier edificio, apoyándose sobre los pilares y trasmitiendo a éstos las cargas de forma convencional. La peculiaridad aparece cuando una parte de los pilares en los que se apoya son inclinados (o se convierten en inclinados en algún nivel por debajo del forjado), ésta, por equilibrio de fuerzas, hace que aparezcan otras horizontales en los forjados, que sumadas a las que se producen por viento y terremotos (aunque éste no sea un efecto dominante en Madrid), colaboran a que el edificio se deforme y tienda a volcarse hacia el lado de la inclinación. A partir de este punto, el camino estructural de las cargas cumple una doble misión: trasmitir las fuerzas verticales hasta la cimentación y resistir todos los efectos laterales que tienden "a volcar" el edificio. A esta estructura principal Leslie Robertson la denominó "megaestructura".

La megaestructura no es un elemento único, sino que en realidad es la suma de la conjunción de distintos mecanismos estructurales que producen el requerido "nivel adecuado de rigidez y resistencia laterales". Los mecanismos principales que LERA incorporó en el diseño son:

.El entramado formado por las vigas y pilares metálicos que, además de trasmitir las cargas hasta la cimentación al estar configurado como una estructura triangulada, posee una rigidez apreciable ante esfuerzos laterales.

.El conjunto de muros que conforman los huecos de ascensores y de instalaciones, configurados como un núcleo central de hormigón que, actuando como viga en voladizo, hace de "mástil interior", confiriendo su rigidez al conjunto (un $80 \%$ del total, frente al $20 \%$ proporcionado por la estructura metálica).

.Los cables postesados incluidos a lo largo de los pilares de la fachada trasera, que en adelante se denominará postesado principal, introducen una importante fuerza inclinada en la coronación del edificio. Dividiendo esta fuerza inclinada en sus componentes vertical y horizontal, se ve que la parte vertical se trasmite directamente a cimentación a través del núcleo de hormigón, mientras que la horizontal produce un efecto opuesto al de la inclinación, reduciendo los esfuerzos y deformaciones provocadas por ésta, "devolviendo" el edificio a su posición "vertical".

.Todo el extremo superior de la estructura que abarca la altura ocupada por la planta técnica hasta el peto, está formado por un importante conjunto de fuertes vigas en celosía (de hecho las vigas más pesadas de la obra se encuentran en este nivel) con una extraordinaria rigidez y es el encargado del reparto y trasmisión de las fuerzas horizontales debidas al postesado principal. 


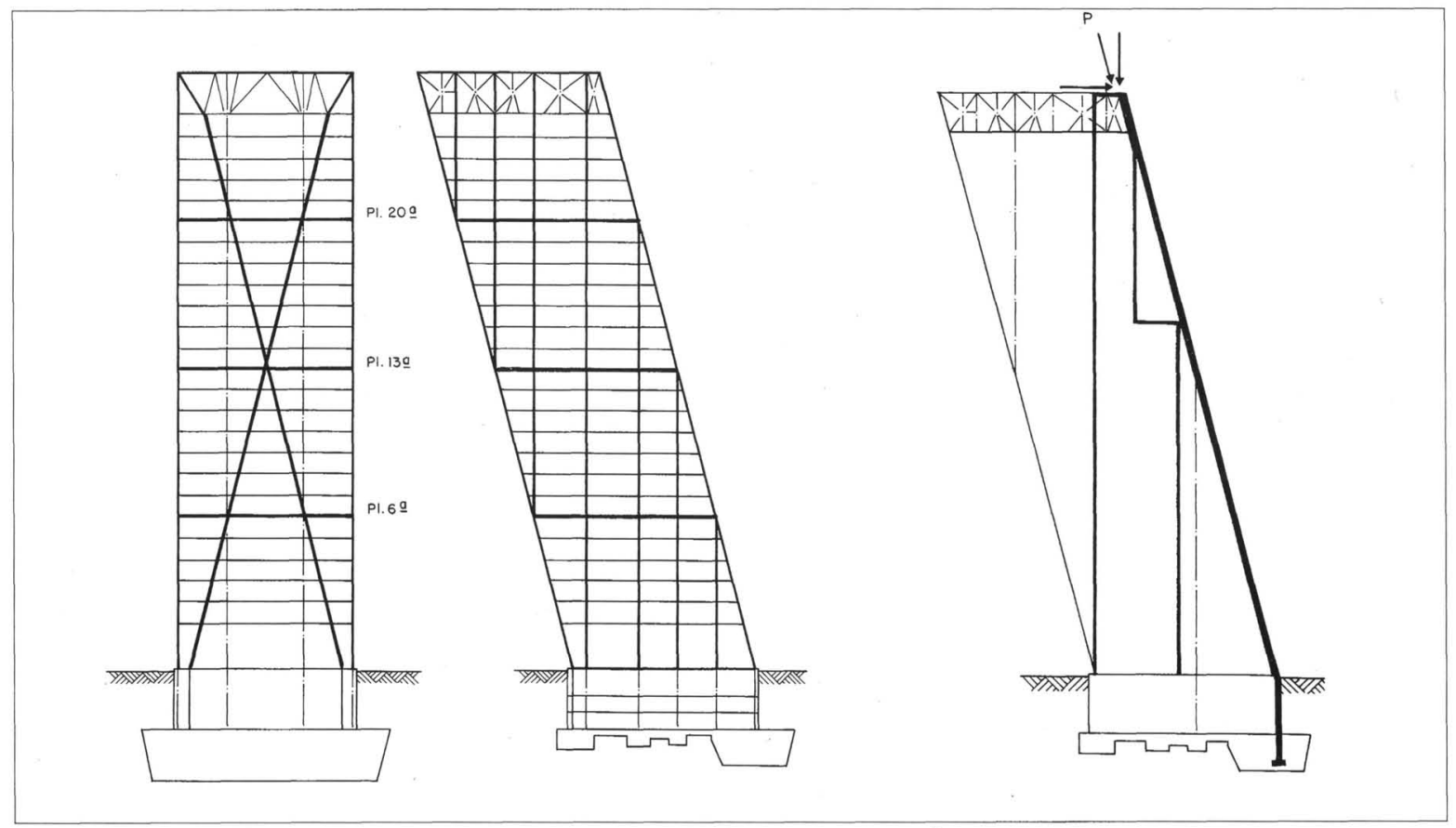

Esquema de estructura en fachadas y funcionamiento del postesado.

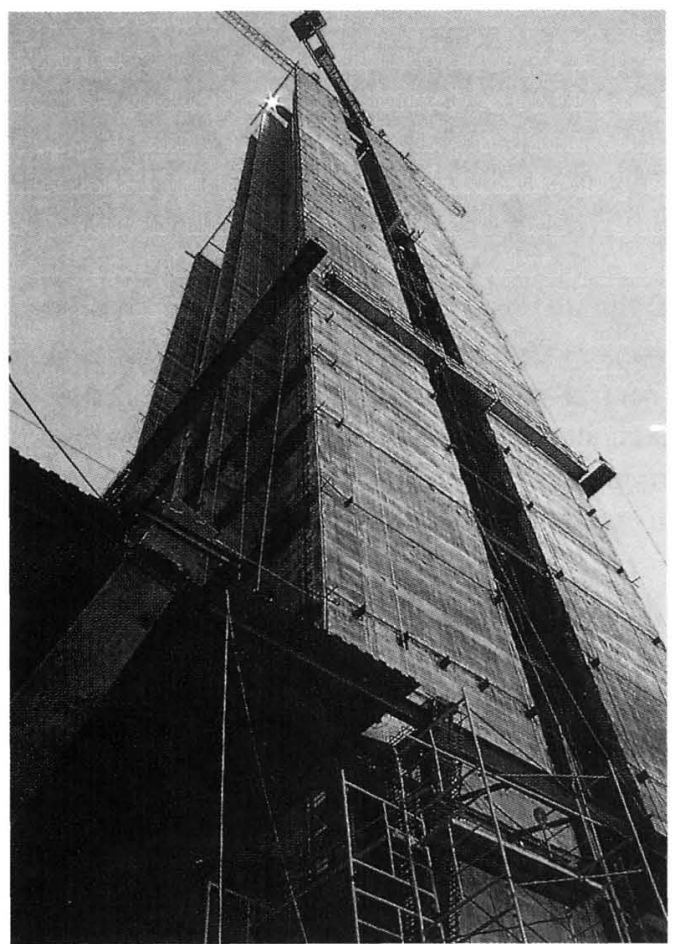

El núcleo.

El conjunto formado por todos estos mecanismos es capaz, por tanto, de resistir las fuerzas exteriores con un nivel admisible de desplazamiento (que se pueden controlar en el futuro gracias a los cables dejados en reserva dentro del conjunto del postesado) y llevarlas hasta el nivel de cimentación.

(c) Consejo Superior de Investigaciones Científicas Licencia Creative Commons 3.0 España (by-nc)
La cimentación cumple también un doble papel en este diseño. Además de repartir las cargas sobre el terreno que las resiste, debe proporcionar al conjunto el nivel de estabilidad necesaria, motivo éste que obliga a la disposición de un potente contrapeso que contrarreste los momentos de vuelco producidos por la inclinación.

Este contrapeso de 15.000 toneladas en cada torre, en un dado de $60 \times 10 \times 10 \mathrm{~m}$, que queda enterrado por debajo del nivel de solera, sirve además para el anclaje de los cables del postesado principal que lo solidarizan a la estructura.

Aunque su ubicación en el edificio final no sea visible, el contrapeso es, por dificultad de ejecución e importancia estructural, uno de los elementos clave con el núcleo del diseño de la estructura de las torres.

El resto de la cimentación cumple su misión mediante encepados y pilotes de hormigón armado. Los pilotes, que podríamos definir como columnas de hormigón introducidas en el terrene, reparten la carga a profundidades de hasta $20 \mathrm{~m}$ por debajo de la solera. Los encepados distribuyen la carga de cada pilar entre los pilotes que la soportan.

Entre estos encepados hay uno de ellos que destaca por sus dimensiones: es el que soporta el núcleo. Con una carga vertical superior a las $35.000 \mathrm{t}$ este encepado del núcleo necesita 28 pilotes repartidos en una superficie de $19 \times 19 \mathrm{~m}$ y requiere de más de 4.000 t de hormigón.

Este es, en resumen, el esquema estructural de unos edificios que, debido a su complejidad, han sido sometidos 
a unalarga serie de resistentes estudios y pruebas, incluyendo maquetas en túnel de viento. Se puede afirmar que el nivel de seguridad alcanzado lo poseen muy pocos edificios en España o cualquier otro país del mundo.
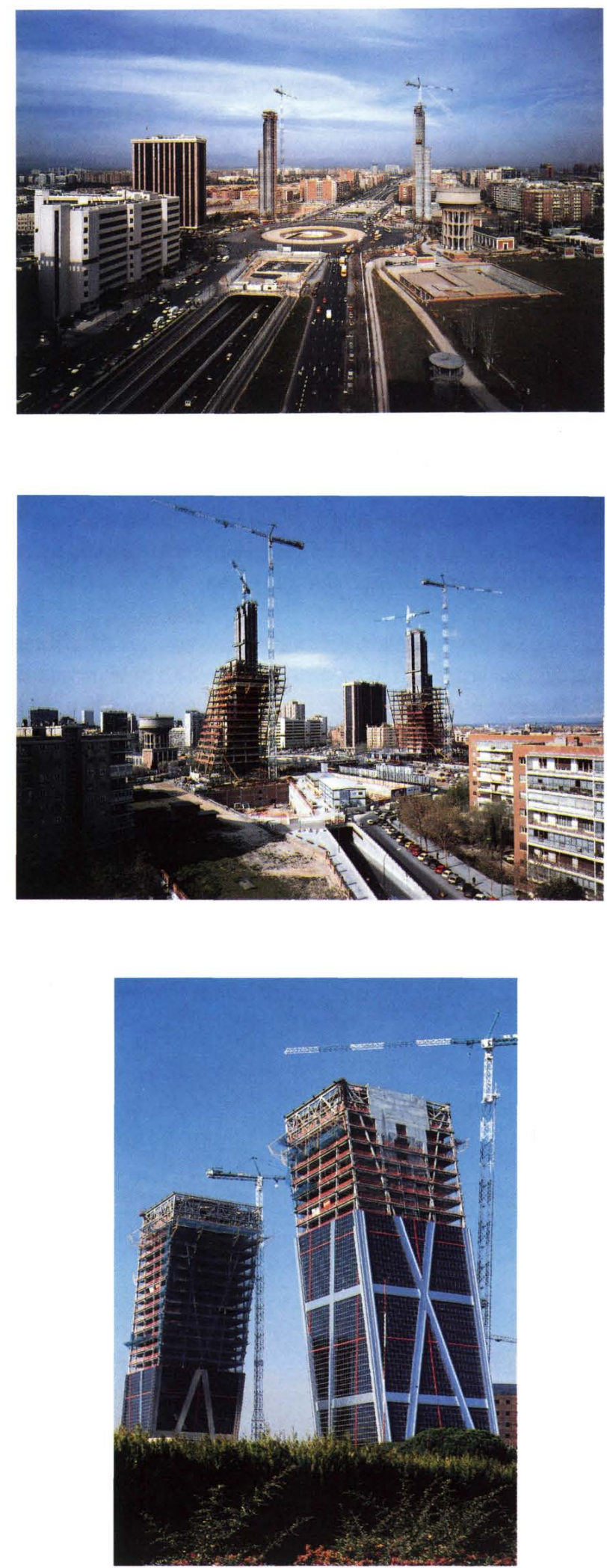

Alzamiento de las torres. Fases del mismo.

(c) Consejo Superior de Investigaciones Científicas Licencia Creative Commons 3.0 España (by-nc)

\section{La construcción}

No existía, ni aún existe, precedente de una construcción similar: de los medios humanos, técnicos, materiales y muy especialmente de seguridad, que serían necesarios y de los problemas de todo tipo que en la obra se podían presentar. Había que desarrollar el proyecto de construcción, planificar y ejecutar la obra. Todo ello con la lógica urgencia que la entonces propietaria, URBANOR, imponía para rentabilizar su inversión lo antes posible.

Pero nada de ello fue obstáculo para que el grupo de arquitectos, aparejadores, ingenieros, etc., incitados por la magnitud del reto planteado, se aplicaran a la tarea de conseguir alzar las torres de Puerta de Europa.

\subsection{Vaciado de solares}

Se confirmó la impresión de que las dificultades propias del diseño no eran suficientes. La ejecución de la obra encontró, en las primeras fases, otra serie de obstáculos que impidieron un normal desarrollo de los trabajos.

Toda obra urbana suele tener siempre inconvenientes con los temas de servicios e instalaciones (luz, agua, gas, teléfonos, etc.). En este caso, el vallado de los solares que se iban a edificar había dejado, durante muchos años, más espacio libre en las aceras que el suyo propio, permitiendo que, a lo largo de ellos, distintas obras de canalizaciones de servicios invadieran la propiedad privada. Se hizo necesario, por tanto, proceder a su desvío antes de excavar los sótanos en esas zonas. Estos desvíos de servicios, realizados en conjunto con los necesarios para la construcción de los pasos subterráneos, dieron lugar a que varias zonas de la obra no estuvieran disponibles para trabajar en el momento que la secuencia lógica lo demandaba.

La mayoría de estas instalaciones eran conocidas pero, en algunos casos, aparecieron "sorpresas" en el desarrollo de los trabajos, obligando a realizar nuevos desvíos y por tanto a modificar las planificaciones de obra. Fue el caso de la galería de saneamiento que, a más de $30 \mathrm{~m}$ de profundidad, cruza la parcela y sirve para el vaciado del depósito del Canal de Isabel II.

Algo similar ocurrió con unas viviendas prefabricadas existentes en el límite de la parcela de la torre oeste. Situadas en lo que algún día será la Avenida de Asturias -que conectará la Plaza de Castilla con el barrio del Pilar y la zona de la Vaguada-, sus ocupantes estaban pendientes de realojos. Invadían también, en algunos casos, parte de los terrenos privados y para la ejecución de la torre debían ser desmontadas, con los problemas que siempre implican los realojos. Necesariamente afectó con serios retrasos al normal desarrollo de la obra. 
Aunque en buena parte eran ya conocidas antes del inicio de los trabajos, otro de los graves inconvenientes de arranque de la obra fueron las importantes interferencias que se presentaron con las instalaciones del Metro. Todo el subsuelo de la Plaza de Castilla está recorrido por sus numerosos túneles. La confluencia de tres líneas en la plaza, con sus correspondientes estaciones, las galerías peatonales de acceso a las mismas y de intercomunicación entre ellas, las de instalaciones, cables, etc. y la existencia de unas cocheras en la trasera de la torre oeste, habían invadido también lo que son los límites de las parcelas edificables, con la particularidad de que estas instalaciones no son fácilmente desviables.

La construcción debía, por tanto, respetar el trazado de las galerías que, fundamentalmente en la torre este, atraviesan el subsuelo de la parcela por debajo de los sótanos y en los casos de las que discurren más superficialmente, atenerse al contorno real de la misma. Ello implicó, como se verá, serias complicaciones y afecciones al diseño y ejecución de les elementos de contención de tierras y de la propia cimentación de los edifícios.

Para la ejecución de los muros se optó, en general, por muro-pantalla de hormigón armado ejecutado in situ. Este sistema consiste en la apertura desde la superficie del terreno-mediante una excavadora especial denominada bivalva- de un pozo de varios metros de longitud en planta, con un ancho que depende del cálculo, pero que en general era de medio metro, y que profundiza hasta por debajo del nivel máximo de la excavación, donde va a quedar empotrado. En él se introduce la "jaula" de barras de acero de refuerzo, necesaria antes de proceder a su hormigonado, con el que se termina el panel de pantalla. Ejecutando varios de estos paneles uno junto a otro, se consigue obtener un recinto excavable para la ejecución de los sótanos.

En función del tipo de terreno y de la profundidad de los sótanos a excavar es usual, como en este caso, que las pantallas para contener las tierras necesiten ser temporalmente sujetas, hasta que se realice la construcción de la estructura de los sótanos, en los que finalmente se apoyarán. Esta sujeción temporal, tanto por la importante longitud del recinto -la excavación incluía la de las parcelas para los vecinos edificios de apartamentos-, como por la variabilidad de los condicionantes exteriores, hubieron de realizarse por muy distintos métodos: bermas provisionales de tierras que debían ser retiradas con la estructura ya construida, apuntalamientos con potentes estructuras metálicas, anclajes al terreno con cables de acero inyectados y tensados, etc.

Realizados todos estos trabajos, se pudo ejecutar la excavación de los solares hasta unos $10 \mathrm{~m}$ por debajo del nivel de la calle, profundidad a la que se debía ejecutar el suelo del tercer sótano y desde la que se acometerían los trabajos de cimentación de las torres.

\subsection{Cimentaciones-contrapeso}

Muchos eran los distintos elementos a realizar dentro de los trabajos de cimentación antes de poder "despegar" con la construcción del edificio.

La ejecución en cada torre de los casi sesenta pilotes en los que se apoyan los encepados; con una longitud total que supera el kilómetro, se realizó con la misma técnica que los paneles de pantalla, esto es, excavación del pozo con la excavadora bivalva y colocación de la jaula de armadura y hormigonado del pozo, con secciones en general de $3 \times 1 \mathrm{~m}$ y profundidades cercanas a $10520 \mathrm{~m}$.

Sobre las puntas de los pilotes que quedaban sobresaliendo del fondo de la excavación, se construyeron los correspondientes encepados. Estos "dados" de hormigón armado tienen, en algunos casos, unas dimensiones tan importantes que no se consideró viable su ejecución en una sola fase, por lo que los encofrados o moldes para su ejecución se tuvieron que completar con paredes intermedias realizadas con una tela metálica especial muy tupida, que ha permanecido luego adherida a la superficie del hormigón asegurando, al hormigonar las sucesivas fases, el posterior monolitismo del conjunto.

En el caso del encepado del núcleo que con sus 28 pilotes sus $361 \mathrm{~m}^{2}$ y sus $4,5 \mathrm{~m}$ de altura, es mucho más propio de la cimentación de la pila de un gran puente que de trabajo de edificación, usualmente de dimensiones mucho más reducidas. Este encepado se dividió en tres partes para su ejecución. Aun así, los más de 540.000 litros de hormigón

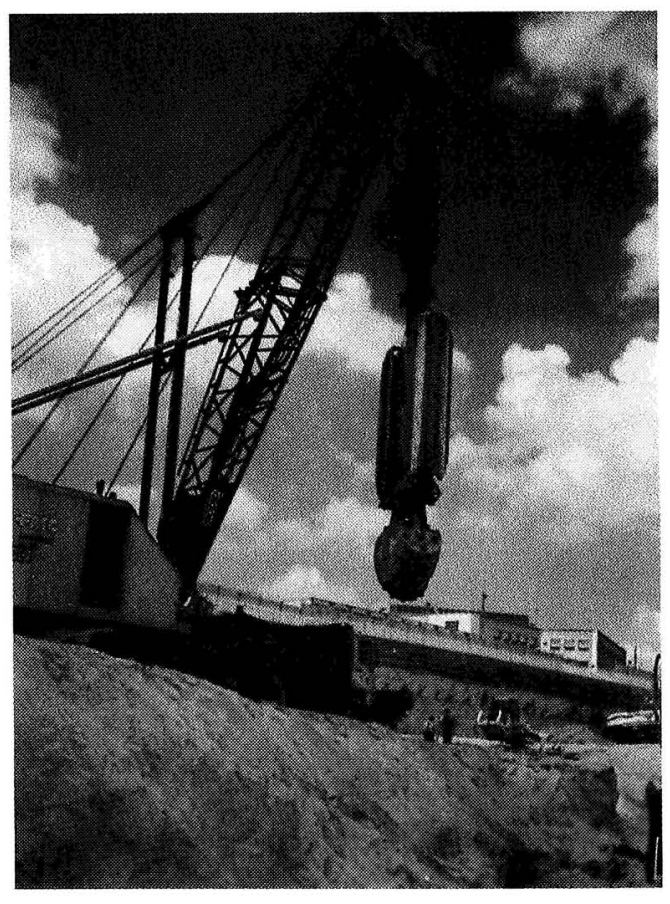

Excavadora bivalva 
a colocar en cada fase, suponían una jornada completa de trabajo sin descanso, al impedir las especificaciones del proyecto que hubiera interrupciones que cortaran la continuidad del hormigonado.

El resto de encepados, de dimensiones algo más reducidas, se hormigonaban en una sola fase sobre sus correspondientes pilotes. En cada uno de ellos se disponían las barras de espera y anclaje, necesarias para la fijación de los muros y de las placas de apoyo de los pilares metálicos que nacen sobre los encepados.

Como se ha dicho al describir el diseño estructural del edificio, el contrapeso es su elemento fundamental, cumpliendo dos misiones en paralelo: por una parte, sus 15.000 toneladas de peso proporcionan a la estructura la estabilidad necesaria para que no se vuelque hacia el lado de la inclinación; por otra, es el lugar de ubicación de los anclajes inferiores del postesado principal.

Como en el caso del encepado del núcleo, las dimensiones de este contrapeso se salen totalmente de lo usual y, por tanto, requirió técnicas especiales para su ejecución.

La realización de un macizo de hormigón de $60 \mathrm{~m}$ de longitud por 10 de ancho y otros 10 de profundidad, situado en el fondo de la excavación realizada para los sótanos, podía conllevar problemas, incluso de estabilidad del recinto de pantallas exterior, por lo que, para la decisión final acerca de los métodos constructivos, se tuvieron en cuenta condicionantes mucho más restrictivos que los normales

Para llevar a cabo la excavación del hueco que posteriormente se rellenaría con los $6.000 \mathrm{~m}^{3}$ de hormigón, se construyeron en primer lugar paneles de pantalla de un metro de espesor que conformaron el recinto correspondiente. En estos paneles, antes de su hormigonado y para asegurar su comportamiento conjunto con el resto del macizo, se dispusieron una serie de tablones de madera que, acabada la excavación, se retiraron, quedando en el paramento interior del recinto de pantallas una superficie dentada de mucha mejor adherencia.

Limitada por este recinto de pantallas, se realizó la propia excavación del contrapeso. Durante la excavación se fueron disponiendo dos niveles de apuntalamientos metálicos mediante potentes perfiles de acero laminado. Estos perfiles, absolutamente necesarios para la estabilidad de las pantallas, suponían, sin embargo, un importante obstáculo en la labor de las máquinas excavadoras utilizadas, ralentizando notablemente su trabajo.

Una vez que se logró hacer el vaciado completo de lo que sería el contrapeso, se estuvo en condiciones de, colocando todos los elementos de armaduras de refuerzo, anclajes de los cables del postesado, etc., comenzar a rellenar el hueco creado.

(c) Consejo Superior de Investigaciones Científicas

Licencia Creative Commons 3.0 España (by-nc)
El relleno del hueco con hormigón, debido a los mismos problemas mencionados para el encepado grande, se tuvo que realizar por fases, dividiendo el bloque total en varias partes, tanto horizontal como verticalmente,

Todos estos trabajos de cimentación que en la torre oeste $o$ "Torre 2" según la terminología oficial del proyecto, se desarrollaron normalmente, en la otra torre (Torre 1) presentaron la complicación añadida de las interferencias con las galerías del Metro. Estas galerías cruzan por debajo de algunos encepados y, fundamentalmente, por debajo del contrapeso. Ello implicó el desarrollo de diseños y procedimientos de construcción especiales que, puenteando las galerías existentes, permitieran la construcción de elementos tan pesados como el contrapeso, encima de galerías subterráneas sin dañar éstas.

Los trabajos de topografía subterránea necesarios para correlacionar al milímetro la situación de las galerías conocidas por los planos del Metro, con la posición de los distintos elementos de la cimentación, permitieron que la construcción de los pilotes que, pasando junto a los bordes de las galerías, trasmitirían las cargas por debajo de ellas, se realizaran sin incidentes importantes. Sólo uno de los pilotes (correspondiente a la cimentación de las estructuras de aparcamientos, no de torre) "pinchó" en el hueco del inicio de una galería ciega que, al no figurar en ningún plano del Metro y estar totalmente tabicada, era desconocida para todos. Al hormigonarse este pilote, la presión del hormigón fresco sobre el tabique de cierre de la galería lo rompió, invadiendo el hormigón una galería peatonal de acceso a la estación, por fortuna sin producir daños personales.

Simultáneamente con los últimos trabajos de ejecución de los contrapesos que finalizaban la cimentación, se comen-

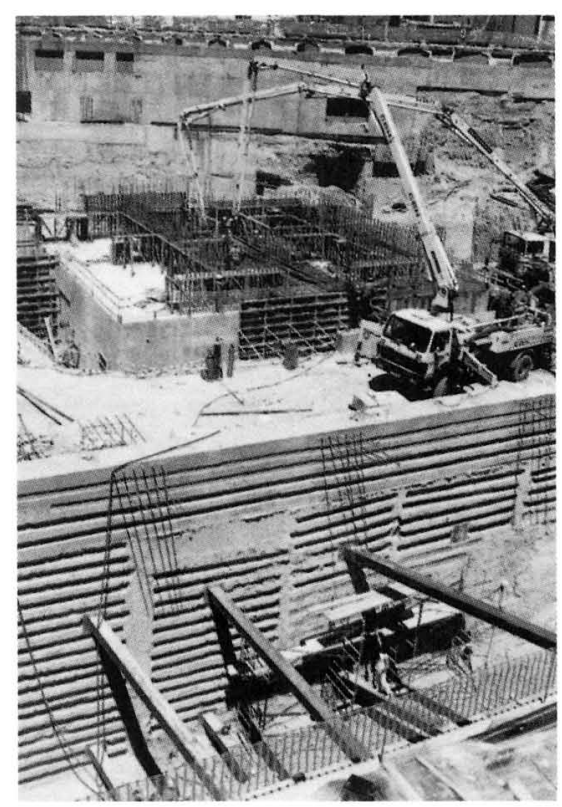

Excavación del contrapeso.

http://informesdelaconstruccion.revistas.csic.es 


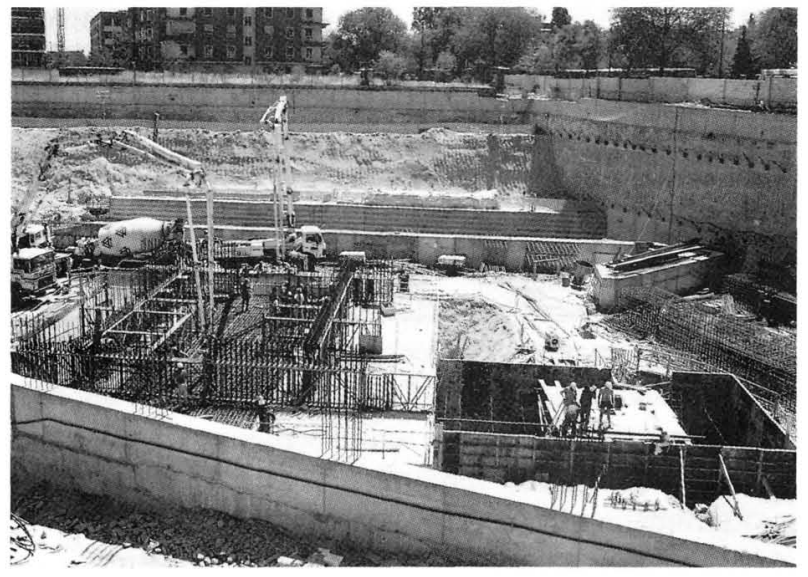

Cimentación de la torre.

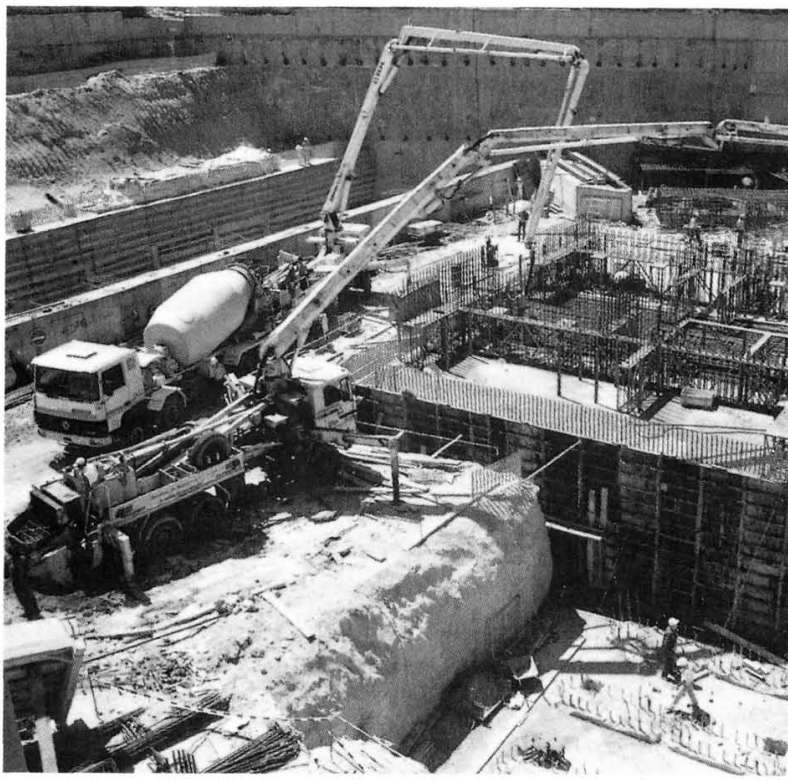

Encepado del núcleo.

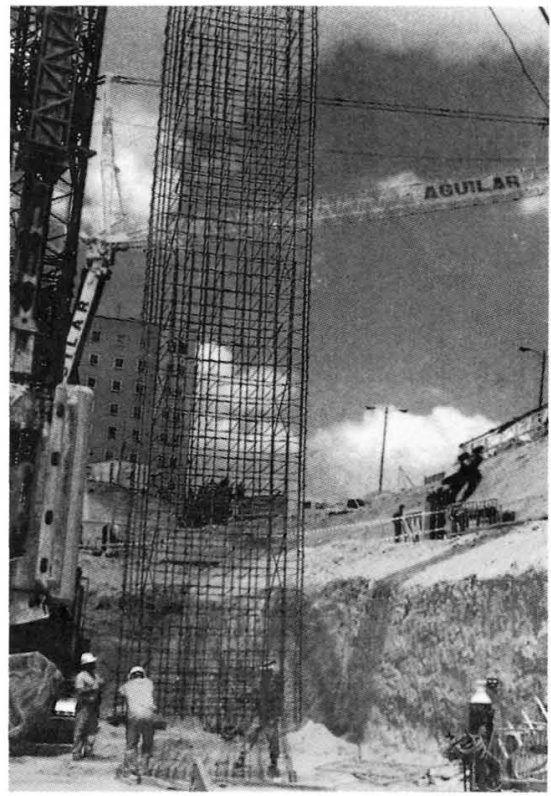

Jaula de armadura de pilote. zó a trabajar en la construcción del núcleo central de servicios.

Este núcleo, verdadera espina dorsal del edificio, tanto estructural como funcionalmente, está constituido por un conjunto de muros de hormigón armado de distintos espesores que delimitan los huecos de ascensores y de instalaciones, adoptando una forma final en planta correspondiente a dos secciones paralelas (para su trabajo como estructura en voladizo) de viga en doble " $\mathrm{T}$ " con nervaduras centrales.

La propia realización de los trabajos de colocación de armaduras y placas, previos al vertido del hormigón en cada momento, requiere una detallada planificación, prácticamente "barra a barra" y un intenso control de la ejecución, pues el hecho del "movimiento continuo" implica que los tiempos disponibles paraestos trabajos sean muy limitados y sin posibilidad de vuelta atrás para correcciones.

Para la ejecución de los núcleos, y ya para toda la obra, se montaron las dos grúas principales (una por torre) que, autoestables con sus casi $150 \mathrm{~m}$ de altura, sin ningún tipo de arriostramiento, sus $60 \mathrm{~m}$ de alcance en planta y sus hasta $16.000 \mathrm{~kg}$ de peso de capacidad de carga, constituyeron una instalación única en España. El montaje de cada una de ellas tardó más de tres semanas, siendo necesarias una decena de personas y dos grúas auxiliares, una de ellas de $300 t$ de capacidad.

Posteriormente, en la coronación del núcleo, se instaló una segunda grúa por torre, de capacidad y alcance algo menores, que complementó a las principales durante el montaje de la estructura metálica y también para el izado de otros materiales a las plantas. Para el acceso del personal a la plataforma del encofrado deslizante, se instaló un ascensor de obra por torre, con capacidad para 20 personas $(1.500 \mathrm{~kg})$, que posteriormente se utilizará para las distintas plantas hasta la entrada en servicio de los ascensores definitivos.

Se había conseguido, tras un año largo de trabajo, "salir del hoyo". Atrás quedaba el esfuerzo realizado para bajar hasta el fondo de los sótanos y construir una complicada cimentación, salvando todos los problemas. Las torres, por fin, empezaban a verse.

Durante las últimas fases del deslizado de los núcleos y simultáneamente con ellos, se procedió al montaje de la estructura de los sótanos, tanto la parte exterior correspondiente a aparcamientos, como la interior al perímetro de la torre. Esta estructura de la zona interior, todavía vertical, se compone de un entramado de pilares y vigas metálicas, que luego quedó embebido en hormigón en la zona del perímetro, formando unos potentes muros que dan rigidez al conjunto de la base. Por el interior del muro correspondiente a la fachada trasera, guiados a través 
de extrañas piezas de acero, discurren los tubos que alojan los cables del postesado principal.

Cuando estuvieron completamente construidos los núcleos y las estructuras de los sótanos empezaban a crecer, se empezaron los preparativos para el montaje de la estructura metálica que conforma el volumen inclinado. Para ello, y de una forma que constituye una de las peculiaridades que presenta la ejecución de la estructura inclinada, se trazaron las referencias de montaje.

¿En qué consiste estapeculiaridad? Toda estructura, cuando se le aplica una carga, se deforma. En una construcción convencional, los pesos con que se carga durante su ejecución producen deformaciones exclusivamente verticales. En nuestro caso, el peso de la estructura iba a producir que ésta se deformase, en dirección de la inclinación, con movimientos significativos hacia la Castellana (más de $15 \mathrm{~cm}$ en el total de la construcción).

Eldiseño prevé, comoyase hadicho, que estos movimientos se recuperarían al final de la construcción de la estructura, con la aplicación de las cargas del postesado. Esto implicó que el replanteo del montaje de las sucesivas plantas no deba en absoluto corregir las deformaciones producidas por el peso de lo realizado con anterioridad, sino que necesariamente se deba montar "deformada" para, al final, recuperar toda la estructura en paralelo.

En estas condiciones no son válidos los sistemas de replanteo clásicos de obra que, basados en puntos fijos del terreno y conocidas las coordenadas de la posición en las que se debe montar cadaelemento, mediante técnicas topográficas convencionales, permiten situar la pieza en su sitio. En este caso, no se conocían a priori las coordenadas de cada elemento con respecto a puntos fijos del terreno. Medir la deformación de otros puntos ya existentes, por comparación entre su posición teórica y la real para, extrapolando esos datos, corregir las coordenadas teóricas y obtener, para cada punto y en cada momento, las coordenadas modificadas en las que se debía montar, resultaría excesivamente prolijo, suponiendo un freno importante a los trabajos de montaje.

En su lugar lo que se decidió fue utilizar, no bases fijas en el terreno, sino una referencia con respecto a la cual sí conocíamos coordenadas que se mantenían en el proceso de deformación, que era el núcleo. Cuando las plantas inferiores se cargan, producen unas deformaciones de la estructura que necesariamente incluyen al núcleo, desplazándose lo que corresponde en cada planta. Es con respecto al citado núcleo donde podemos establecer referencias fijas de la estructura a montar.

Para ello era necesario, una vez finalizada su construcción, trazar sobre los paramentos de sus cuatro caras referencias de lo que en ese momento, anterior al inicio del montaje de
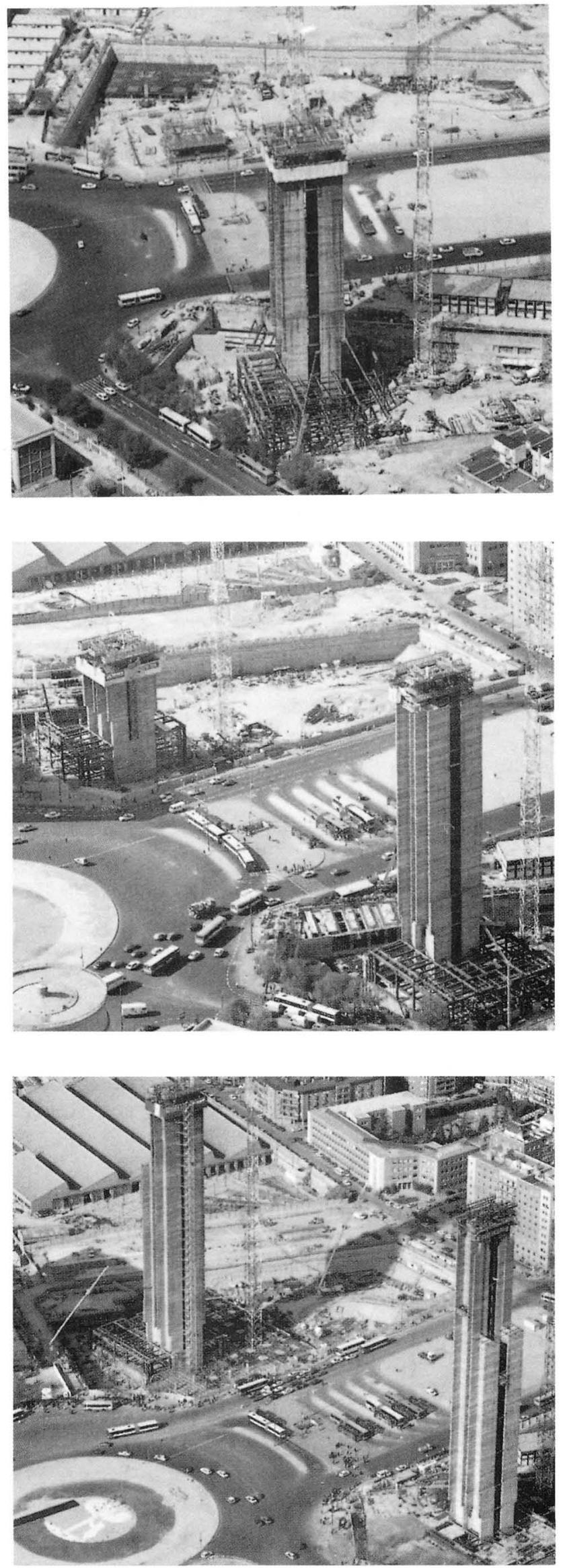

Diversas fases del deslizado. 
la estructura inclinada, eran ejes verticales, con respecto a los cuales se iban a desarrollar todos los trabajos y comprobaciones a partir de entonces. Este trabajo lo llevaron a cabo especialistas de escalada que, colgados con cuerdas por las paredes del núcleo y guiados por topógra- fos desde el nivel del suelo, marcaron esas referencias en el hormigón, que después sirvieron para, durante el montaje, situar los aparatos de medida con que controlar la posición de las piezas instaladas.

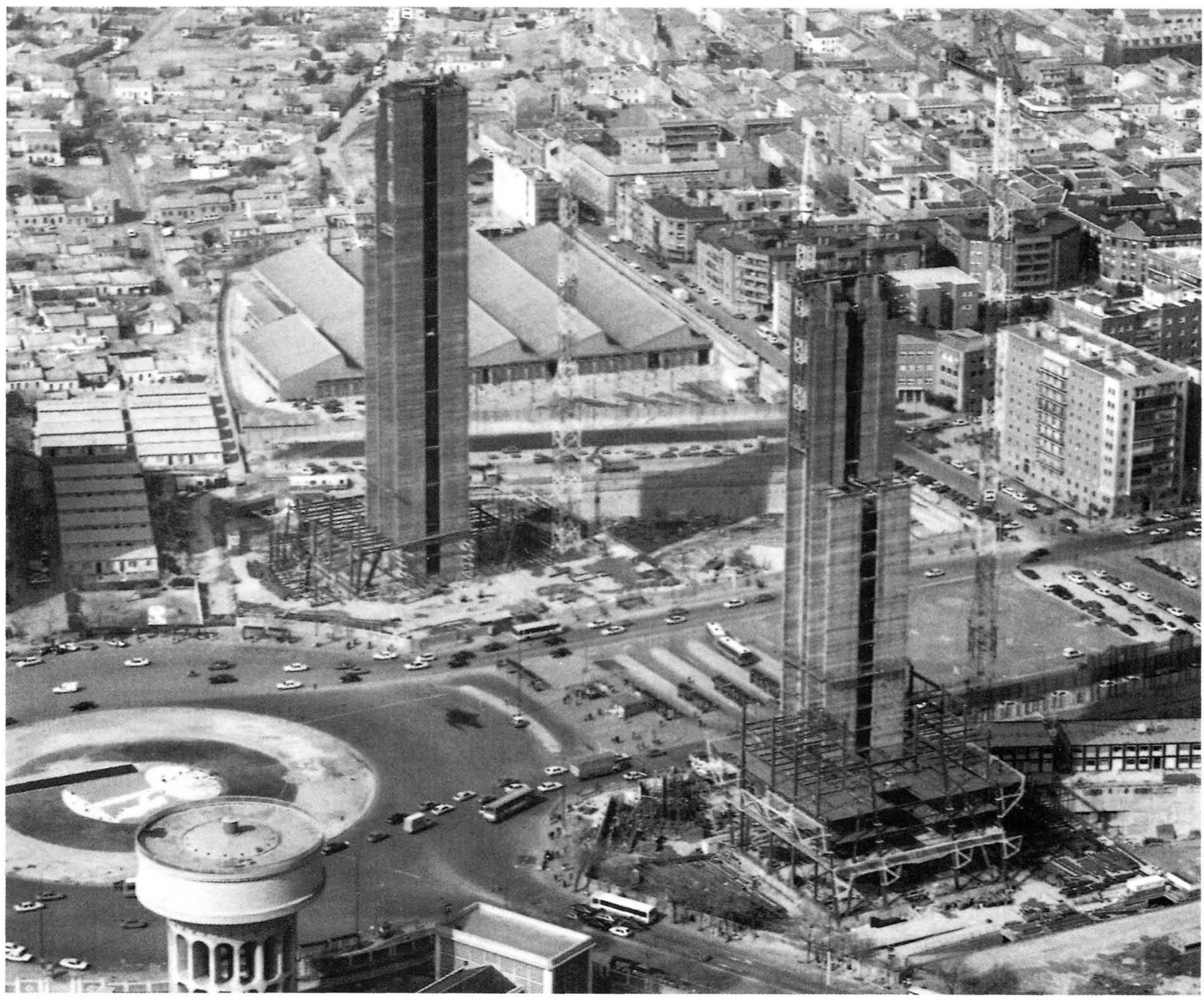

Montaje de estructura.

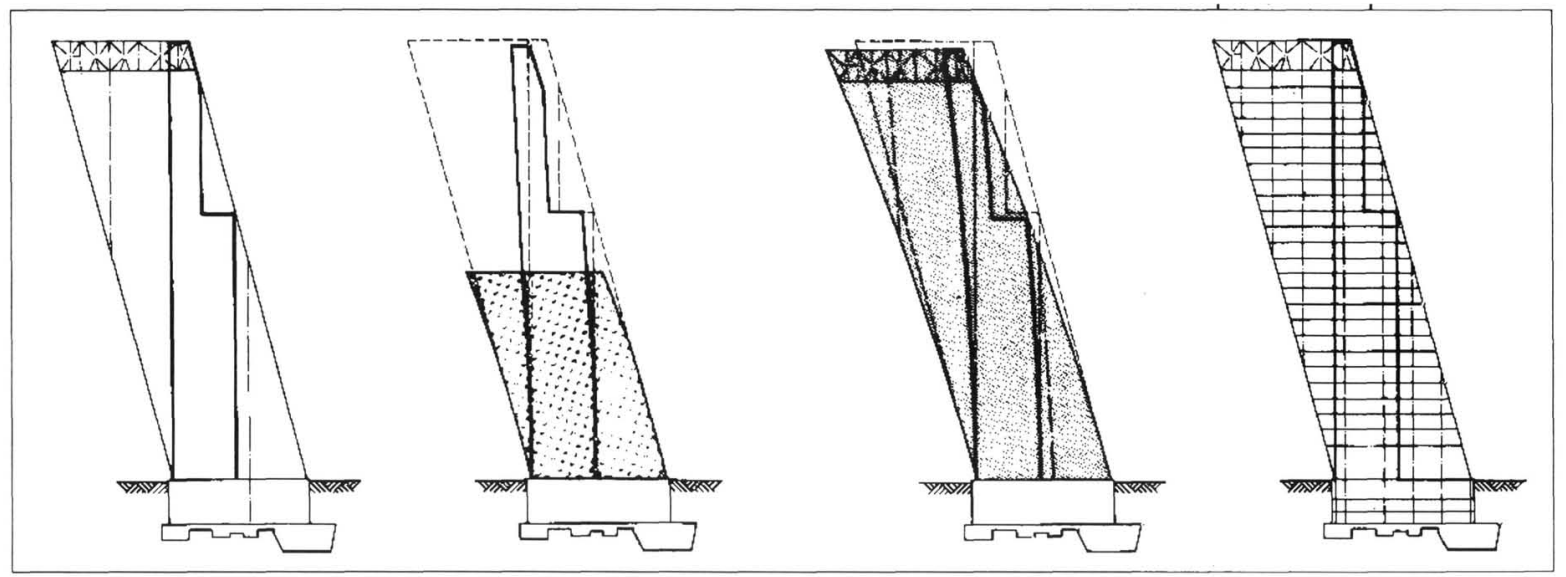

Mientras se construye, el edificio se deforma. Hay que construir deformado para volver después todo a su sitio. 
Formada por perfilería de acero laminado en caliente, las secciones que el diseño imponía no estaban disponibles en el mercado nacional, por lo que fueron suministradas por fabricantes europeos. Las uniones, en su gran mayoría, se proyectaron con tornillos, utilizando los de alta resistencia, con un sistema de control del apriete mediante unas arandelas deformables especiales que, al conseguir la fuerza correspondiente, se aplastaban indicando que la unión era correcta.

Los forjados de planta son de tipo mixto hormigón-acero y se componen de la viguería metálica sobre la que se dispone una chapa de acero galvanizada para protegerla contra la corrosión, con un diseño de formas que permite la perfecta adherencia del hormigón que se vierte sobre ella, consiguiéndose el trabajo conjunto de los dos materiales. La unión de vigas y forjado se logró mediante la soldadura de unos pernos conectores especiales sobre las cabezas de las vigas. E1 hormigón que se utiliza se fabrica sustituyendo la grava convencional por un árido especial de arcilla expandida muy ligero, que permite reducir el peso de la mezcla en un $30 \%$, con el consiguiente ahorro de materiales y de peso total del edificio.

Con el montaje de la estructura, las torres empezaron a adoptar su volumen y forma definitivas, la inclinación empezaba a "asombrar" y comenzaban a surgir los comentarios en la calle.

En la coronación, el diseño dispuso un sistema de entramados metálicos en celosía que en la obra se denominaban las "cerchas de cubierta". Estas cerchas estaban compuestas, al igual que el resto de la estructura, por chapas y perfiles metálicos laminados, pero los grandes esfuerzos que se ponen en juego en esta parte de la estructura, para el reparto de las fuerzas del postesado, provoca que las secciones deban ser mucho mayores y los perfiles utilizados superen a los más fuertes de toda la obra. Chapas de bastantes centímetros de espesor, vigas que pesan más de $900 \mathrm{~kg}$ por metro (una viga usual no llega ni con mucho a $100 \mathrm{~kg}$ ), nudos de unión de perfiles, en los que se utilizan cientos de tornillos de gran calibre, etc., son los elementos de una coronación de edificio que supone, en términos de complicación técnica, un digno remate del mismo

Acabado el montaje de las cerchas y el hormigonado de los muros que en algunas zonas las cubren (muros para los que hubo de instalarse encofrados que "colgaban" sobre el vacío) mientras se completaba la estructura del helipuerto, ya se estaba en condiciones de proceder a la primera de las fases del postesado. En menos de un año, desde que se arrancara el deslizado del núcleo, se había alcanzado la coronación y completado la estructura principal del edificio.

Dado que la función del postesado es oponerse a la acción de vuelco de las cargas verticales (peso del edificio, etc.),

(c) Consejo Superior de Investigaciones Científicas Licencia Creative Commons 3.0 España (by-nc) el proceso constructivo marcaba que, con objeto de no "forzar hacia atrás" la estructura, su carga se introdujera por fases, buscando en lo posible llevarla equilibrada en cada momento con el peso total de la estructura

El sistema de postesado está formado por un total de 24 cables de acero especial, cada uno de ellos formado por 19 cordones de 0,6 pulgadas (algo más de $15 \mathrm{~mm}$ de diámetro), con una capacidad de carga de 505 t por cable (más de
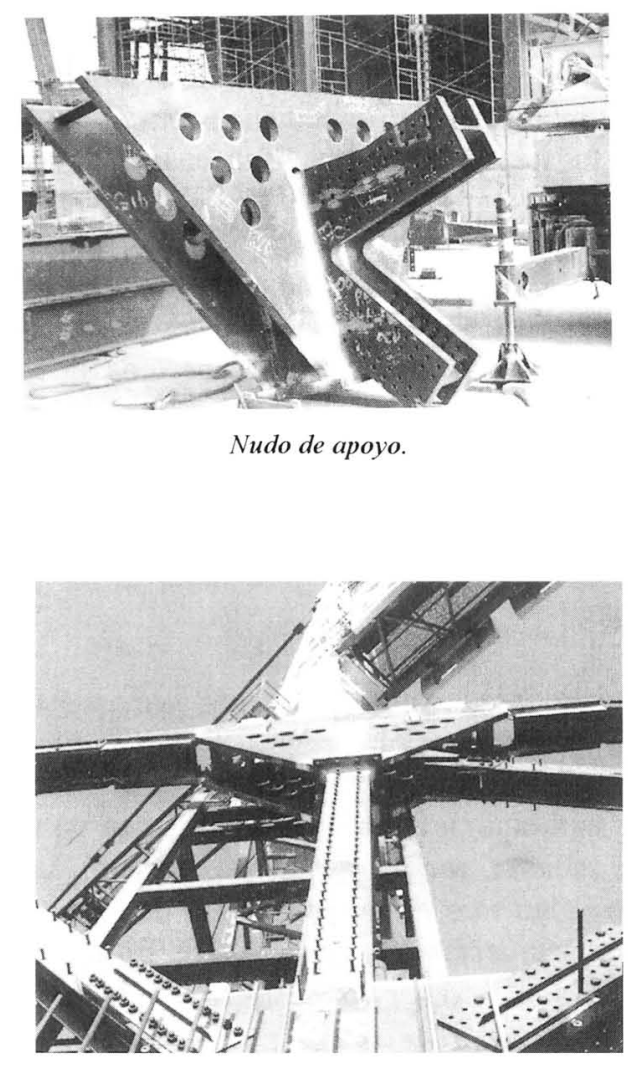

Nudo apoyado sobre la estructura provisional.

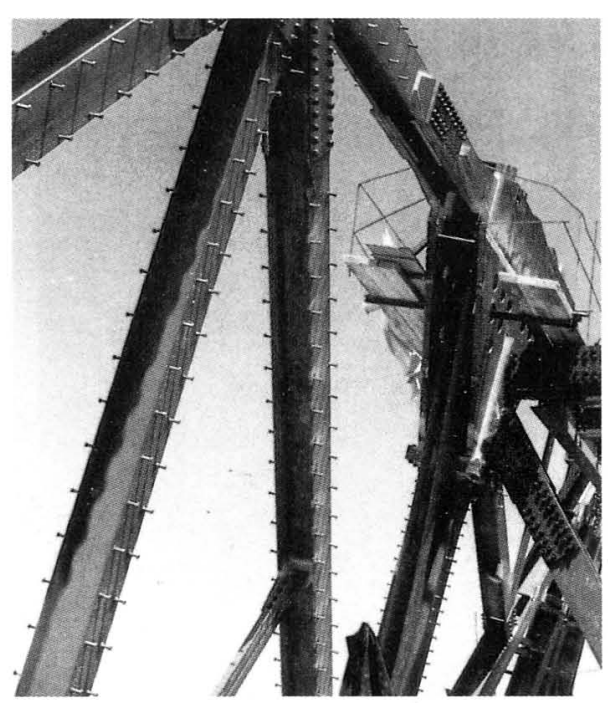

Nudo -ya sin la grúa-con sus vigas definitivas. 
$12.000 \mathrm{t}$ en total por torre). Estos cables que, como se ha visto, se anclan en el fondo del contrapeso, suben por dentro de tubos metálicos hasta la coronación, donde se sitúan los anclajes activos, desde los que se aplica la carga. Con objeto de reducir, en parte, la longitud total de tesado, a nivel de sótanos se dispusieron anclajes de continuidad, que actúan como empalmes del cable a media altura.

La carga del postesado se introduce mediante la utilización de unos potentes gatos hidráulicos, que estiran el cable mientras se apoyan en la estructura. El esfuerzo de estirar los cables inclinados (en este caso el alargamiento del cable, debido a la tensión, era próximo al metro), al fijarse éstos sobre las correspondientes placas de anclaje, produce las fuerzas deseadas que se oponen al vuelco del edificio.

Las fases de postesado aplicadas son dos por torre. La primera, realizada nada más completar la estructura de coronación, contrarrestaba el peso de toda la estructura construida hasta el momento (aún restaba el hormigón de un par de plantas y del helipuerto) y mediante el tesado de 16 de los 24 cables, recuperó los más de $12 \mathrm{~cm}$ que la estructura había deformado hacia la Castellana, dejando la coronación dos centímetros más atrás de su posición "vertical".

La segunda fase, realizada algunas semanas después, corregía la deformación producida por el peso de la estructura pendiente de realizar en la fase anterior y por el peso de la maquinaria de instalaciones que ya se había izado a cubierta, cargas por la que, en total, las torres perdieron algo más de un centímetro de lo que habían quedado hacia atrás en la primera fase. En esta segunda

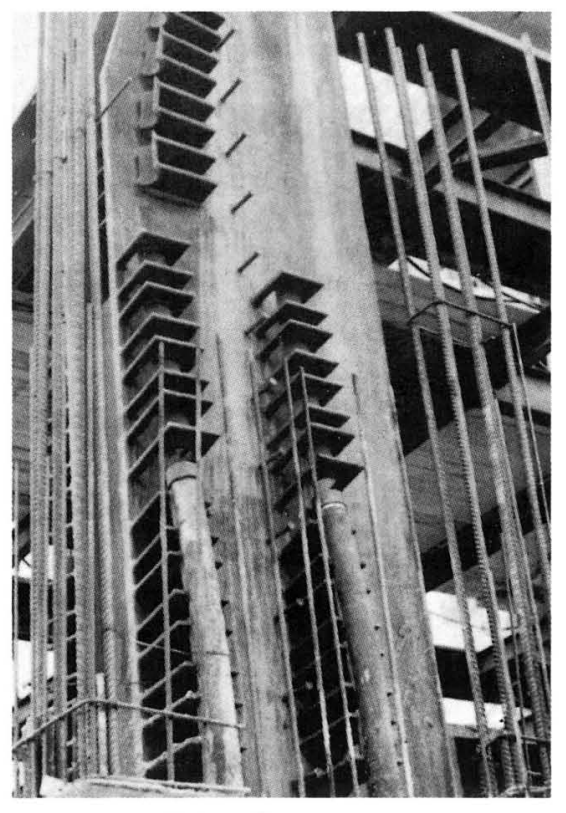

Vainas de postesado.

(c) Consejo Superior de Investigaciones Científicas Licencia Creative Commons 3.0 España (by-nc) fase se tesaron cuatro cables, llevando al edificio, al final, hasta casi cinco centímetros más allá de su "teórica verticalidad" en previsión de los pesos como fachadas, instalaciones, suelos, techos, etc. que aún quedaban por introducirse en la estructura

Quedan, por tanto, otros cuatro cables por torre sin utilizar y que se dejarán como reserva para el futuro en previsión de problemas, incrementos de carga por cambio de uso, etc y que confieren un importante nivel de seguridad adicional

Ha sido ésta una obra modélica en los temas de seguridad y ello pese a que el nivel de riesgos fue extraordinario por realizarse trabajo en altura, con los peligros que conlleva, agravándose en este caso por el hecho de que se desarrollaron justo en el límite del terreno asignado a la obra, con lo que cualquier material, herramienta, etc. que pudiera caerse desde la altura podía alcanzar a personas o vehículos, con consecuencias incalculables.

A lo largo de toda la obra se había buscado, con el objetivo de acortar los plazos, solapar en lo posible las distintas actividades. En este sentido, se creó lo que se podría llamar un "tren de montaje", como una cadena, pero con la diferencia de que en este caso los que se mueven son los operarios y no los productos que se fabrican. Así, de forma ordenada, todos los que tenían que trabajar en cada planta, hasta completar el entramado de tubos, cables, conducciones, etc. iban entrando, realizando su trabajo y permitiendo que el siguiente en la cadena pudiera realizar el suyo.

Poco a poco los techos de las plantas se llenaron de instalaciones, mientras que por el interior del núcleo los primeros ascensores comenzaban a funcionar tomando el relevo del montacargas de obra. En los sótanos y la cubierta, los grandes equipos centrales iban tomando forma. Las calderas, grupos frigoríficos, bombas, ventiladores, grupos electrógenos quedaban instalados y se iban conectando entre sí para completar las instalaciones.

Mientras tanto, por el exterior, la torre se empezaba a vestir. Los paneles de aluminio y vidrio que forman las fachadas salían de sus embalajes y, puestos en su lugar, cubrían las líneas de la estructura. Las esquinas se cubrian con acero inoxidable, formando los machones característicos del diseño. Los madrileños empezaban a ver el aspecto final de las torres y nada parecía ya interponerse en el camino para la terminación de la obra.

Pero ya se sabe que el dinero es el motor del mundo y lo que ni la complejidad del diseño ni las dificultades técnicas lograron, lo consiguieron los problemas financieros de la propiedad y, poco a poco, como resistiéndose a lo inevitable, a finales del año 1992 la obra se paró.

Quedó sólo una cuadrilla de mantenimiento que velaba por 


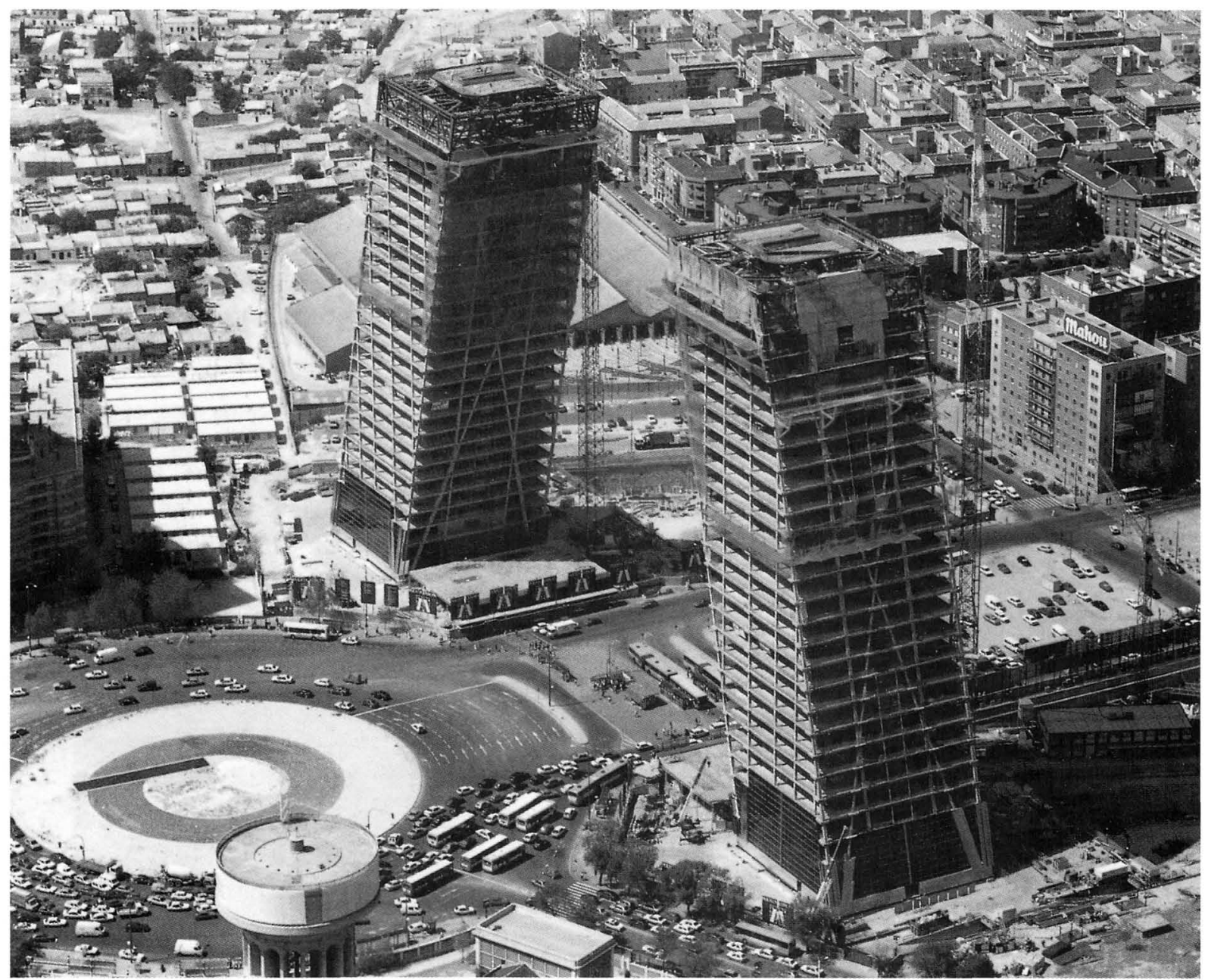

La estructura completa dispuesta para el postesado.

la seguridad de las dos torres vacías, a medio vestir, como dos fantasmas en el paisaje madrileño.

Pero los malos momentos siempre pasan y los problemas de financiación terminaron cuando, tras la compra de las torres en pública subasta, la sociedad PRODUSA se hizo cargo de la terminación de la obra.

Había que volver a comenzar, reorganizar en lo posible un equipo humano que se había dispersado y retomar los proyectos y planificaciones. Fue necesario revisar los posibles daños que las inclemencias del tiempo hubieran causado en la obra y reorganizar acopios y suministro. Se incorporaron nuevas empreśas, nuevos nombres y nuevas caras, pero todos, veteranos y recién llegados, con el claro objetivo de conseguir terminar lo que antes había quedado inconcluso.

Poco a poco la actividad renacía. Tras dos años de paralización los gigantes se despertaban y, nuevamente, técnicos y operarios recorrían su interior. Quedaban muchas cosas por hacer: fachadas, kilómetros de tubos y cables para completar las instalaciones, retomar en cada puntolostrabajos acabados pendientes mármoles y granitos Licencia Creative Commons 3.0 España (by-nc) en vestíbulos, tabiquerías, techos y suelos en oficinas. El vestíbulo de entrada y la urbanización se han rediseñado y hay que empezar de cero, y todo ello, de nuevo, sabiendo que "el tiempo es oro".

La fachada fue creciendo y con la colocación de las últimas piezas en los petos de cubierta, por fin se completaba la piel exterior de las torres. En el interior, los pintores daban el toque final a las plantas. La decoración de los vestíbulos de entrada empezó a tomar forma y en el exterior, en lo que en su día fueron zonas de acopio de materiales, las cajas y los contenedores dieron paso a lo que serán los solados de la urbanización.

Corre el año 1996 y lo que temporalmente fue un reflejo de la recesión, es hoy un proyecto vivo y que, por fin, se ha incorporado de pleno derecho a los símbolos representativos del Madrid del futuro.

\section{El resultado}

Hasta aquí la panorámica de cómo a lo largo de muchos años se gestó y realizó el proyecto Puerta de Europa. 
El resultado es que hoy podemos disfrutar de una Plaza de Castilla totalmente distinta de la que sólo hace unos años conociamos. El entorno se ha recuperado para el viandante. La construcción de los pasos subterráneos ha descongestionado un tráfico que había llegado al nivel de saturación. El intercambiador de transportes ha ordenado la, hasta entonces, caótica situación de paradas de autobuses urbanos e interurbanos.

La nueva situación del monumento a Calvo Sotelo, al sur de la plaza, como extremo del eje de la Castellana, dejando el centro de la glorieta a la nueva gran fuente, hace que la plaza no "se cierre" hacia el interior de la ciudad como antes ocurría sino que, incorporando las grandes superficies urbanizadas, se abra hacia el visitante.

El concepto de puerta que muestra el impresionante volumen de las torres inclinándose sobre la Castellana, preside la entrada norte de Madrid.

Las torres Puerta de Europa son edificios con mentalidad de siglo XXI. Sus $60.000 \mathrm{~m}^{2}$ de superficie de oficinas están dotados de las más modernas instalaciones y medios de seguridad y han sido complementados con las correspondientes superficies de aparcamientos y zonas comunes

Se ha asegurado la comodidad de los futuros ocupantes en unas oficinas insonorizadas, climatizadas e iluminadas, con los requerimientos más exigentes. La seguridad se garantiza con las más modernas protecciones contra incendios, tanto activas (detección y extinción) como pasivas (tratamiento ignífugo de la estructura, compartimentación, vías de evacuación, etc.), y de control de accesos y anti-intrusos, todas ellas coordinadas desde la

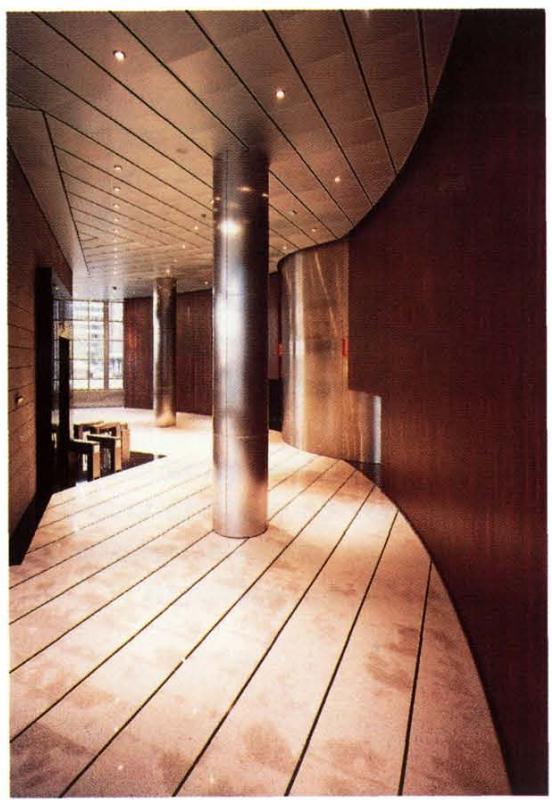

sala de control central de cada edificio. En otra sala, situada también en los sótanos, y dotada de los medios más modernos de inspección, se canaliza todo el tráfico de paquetería, correo y mensajería, como mejora añadida de seguridad.

Los ocho ascensores de gran velocidad de cada torre garantizan un acceso rápido y seguro a los locales de oficinas. Se dispone, además, de dos escaleras para casos de emergencia. Otros dos ascensores por torre cubren el acceso desde los aparcamientos hasta el vestíbulo de entrada.

La magnitud de una obra como ésta es absolutamente impensable abordarla de forma individual. Es el resultado de un intenso trabajo en equipo. Desde el inicio al acabado, la obra ha ido recibiendo mucho de muchos expertos, cada uno en su cometido, trabajando hacia el objetivo común de llegar a construir lo que hoy podemos contemplar: las torres Puerta de Europa.
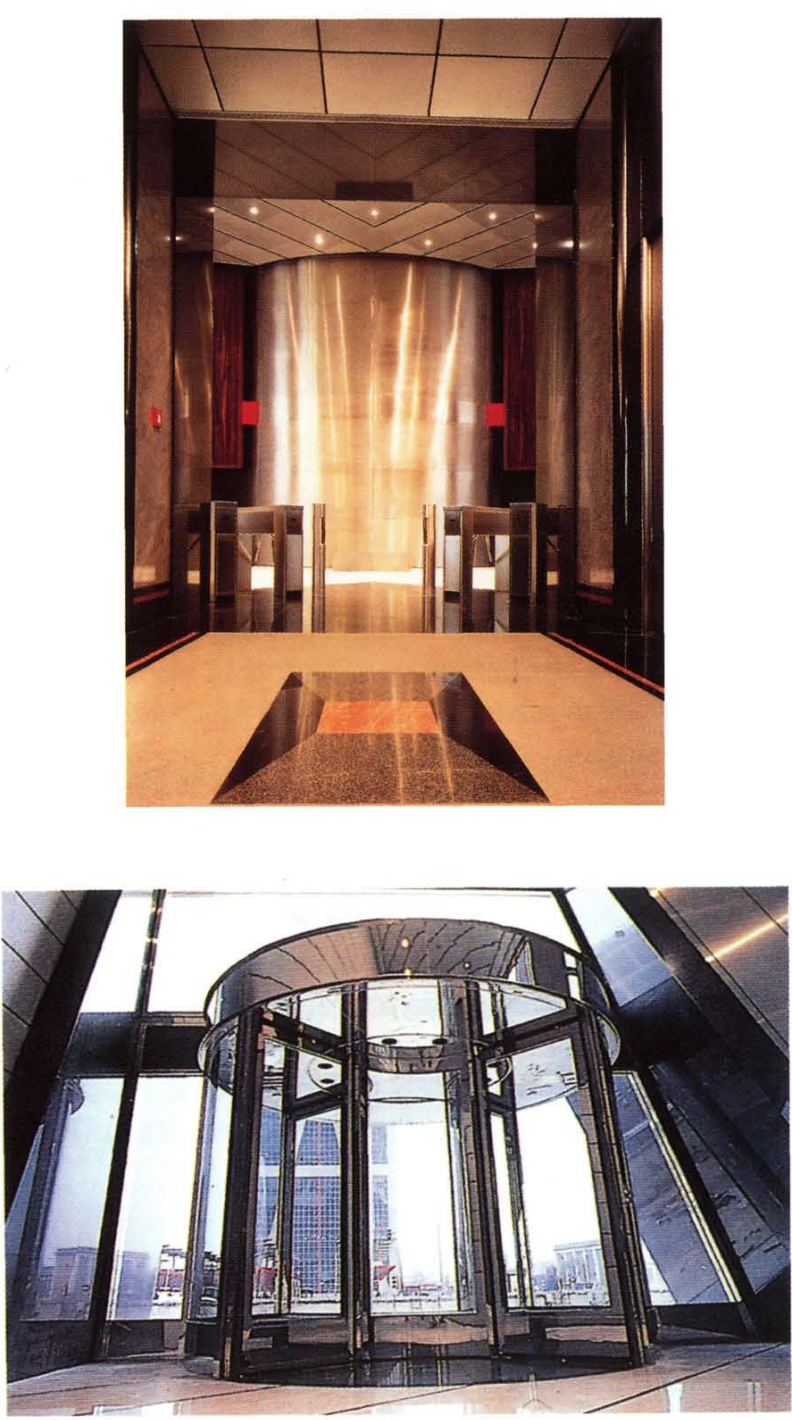

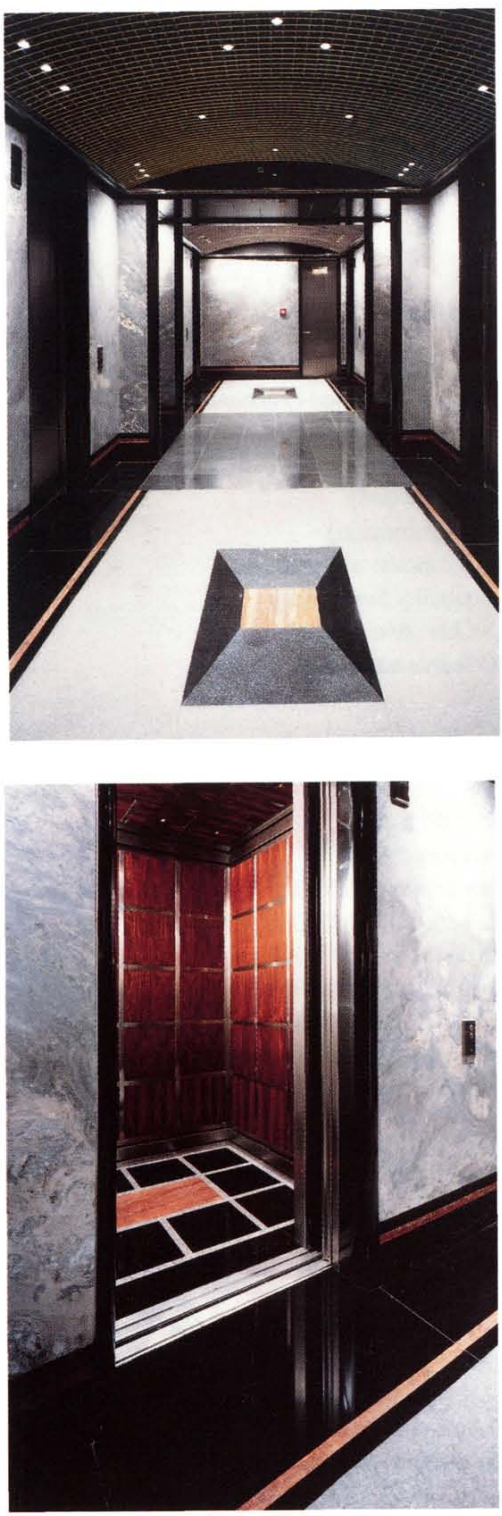
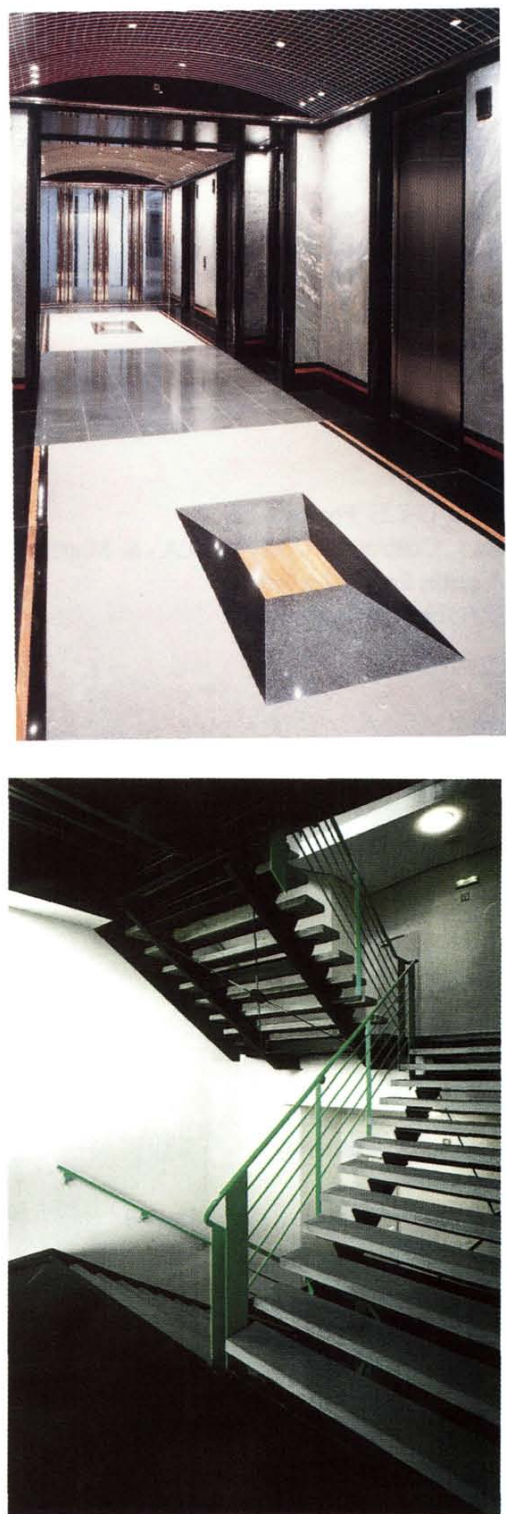

Acceso a los locales.

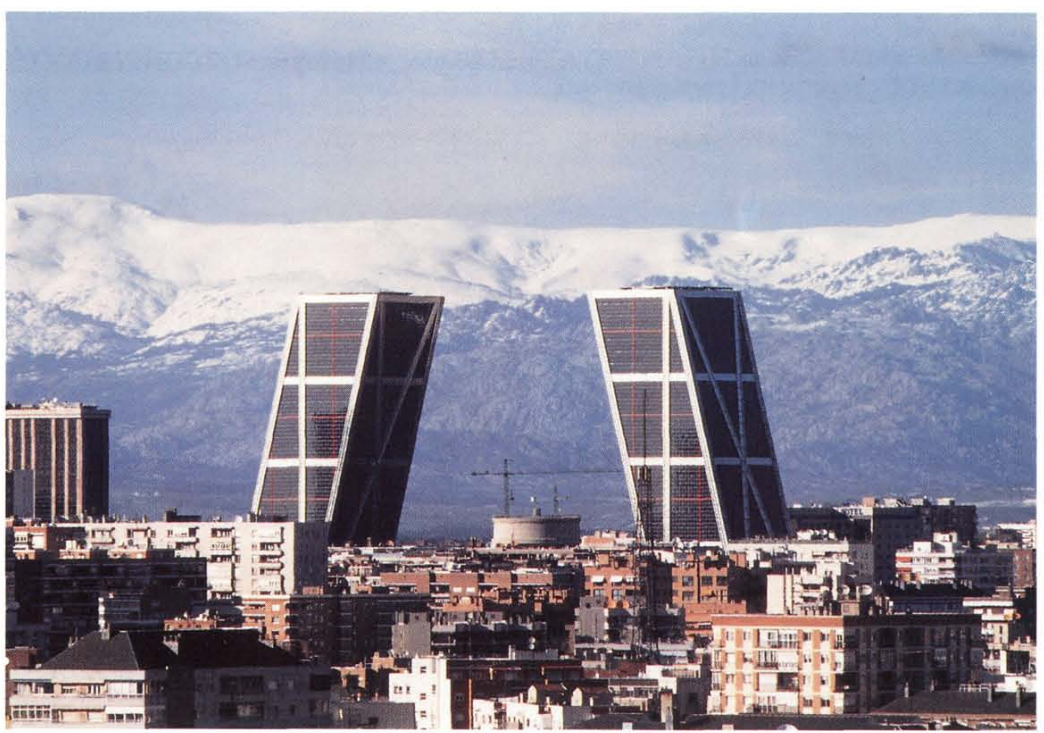




\section{U.T.E. (Contratista)}

URBANOR (Propiedad)

CONTRATISTA: Fomento de Construcciones

y Contratas

GERENTE: Antonio Moyano Paredes

JEFE DE OBRA: Carlos Cordero

\section{U.T.E. (Contratista actual)}

PRODUSA (Produsa)

CONTRATISTA: U.T.E. Fomento de

Construcciones y Contratas - Comylsa, S.A.- S. Martín

GERENTE: Agustín Fernández Arcos

JEFE DE OBRA: Emilio Bargueño

\section{Arquitectos}

Tomás Domínguez del Castillo

Juan Carlos Martín Baranda

\section{Arquitecto Téenico}

Jesús Lizarbe Teres

\section{Autor del Proyecto}

Philip Johnson

Oficina: John Burgee

Ingeniería (Control Estructura)

Jesús Mateos Hemández-Briz (Ing. de Caminos)

Ingeniería

Goymar

Control de Calidad

Intemac

\section{Control Costes y Coordinación}

Eptisa

\section{Subcontratistas}

RBC Holdings/Robertson (Fachada)

Sulzer (Climatización)

Incoclima (Fontanería)

Espelsa (Electricidad)

Años Luz (Iluminación)

Abengoa (Extinción de incendios)

Sainco (Control y Seguridad)

Zardoya - Otis (Ascensores)

Edimon (Piedras naturales)

\section{Volúmenes de la obra}

Hormigón: $127.500 \mathrm{~m}^{3}$

Acero armaduras: $8.000 \mathrm{t}$

Estructuras de acero: $8.900 \mathrm{t}$

Superficie acristalada: $22.000 \mathrm{~m}^{2}$

Superficie de fachada: $33.000 \mathrm{~m}^{2}$

Longitud de cableado: $6.200 \mathrm{~m}^{2}$

Conductos de aire acondicionado: $30.000 \mathrm{~m}$

Fuentes de energía: Suministro en B.T.

$\mathrm{y}$ central térmica $6.000 \mathrm{kVA}$.

\section{Seguridad y Protección contra Incendios}

Rociadores: $4.400 \mathrm{Ud}$.

Detectores: $2.350 \mathrm{Ud}$.

Sistemas contra incendios: 16 centrales

Sistemas de seguridad centralizado:Integración

de todos los sistemas existentes (Aire acondicionado,

ascensores, protección contra incendios,

instalación eléctrica, control y seguridad).

NOTA: El texto delpresente artículoha sidorecogido del libro "PUERTADEEUROPA", editadopor: FCC CONSTRUCCIÓN,S.A.; COMYLSAEMPRESA CONSTRUCTORA, S.A. y CONSTRUCCIONES SAN MARTIN, S.A. 